\title{
Comparison between CARIBIC Aerosol Samples Analysed by Accelerator-Based Methods and Optical Particle Counter Measurements
}

\author{
B. G. Martinsson ${ }^{1}$, J. Friberg ${ }^{1}$, S. M. Andersson ${ }^{1}$, A. Weigelt ${ }^{2, *}$, M. Hermann ${ }^{2}$, D. Assmann ${ }^{2}$, J. Voigtländer ${ }^{2}$, \\ C. A. M. Brenninkmeijer ${ }^{3}$, P. J. F. van Velthoven ${ }^{4}$, and A. Zahn ${ }^{5}$ \\ ${ }^{1}$ Division of Nuclear Physics, Lund University, Lund, Sweden \\ ${ }^{2}$ Leibniz Institute for Tropospheric Research, Leipzig, Germany \\ ${ }^{3}$ Division of Atmospheric Chemistry, Max Planck Institute for Chemistry, Mainz, Germany \\ ${ }^{4}$ Royal Netherlands Meteorological Institute (KNMI), De Bilt, The Netherlands \\ ${ }^{5}$ Institute of Meteorology and Climate Research, Forschungszentrum Karlsruhe, Karlsruhe, Germany \\ *now at: Institute for Coastal Research, Helmholtz-Zentrum Geesthacht, Geesthacht, Germany
}

Correspondence to: B. G. Martinsson (bengt.martinsson@ @uclear.lu.se)

Received: 5 February 2014 - Published in Atmos. Meas. Tech. Discuss.: 1 April 2014

Revised: 4 July 2014 - Accepted: 10 July 2014 - Published: 19 August 2014

\begin{abstract}
Inter-comparison of results from two kinds of aerosol systems in the CARIBIC (Civil Aircraft for the Regular Investigation of the atmosphere Based on a Instrument Container) passenger aircraft based observatory, operating during intercontinental flights at $9-12 \mathrm{~km}$ altitude, is presented. Aerosol from the lowermost stratosphere (LMS), the extra-tropical upper troposphere (UT) and the tropical mid troposphere (MT) were investigated. Aerosol particle volume concentration measured with an optical particle counter (OPC) is compared with analytical results of the sum of masses of all major and several minor constituents from aerosol samples collected with an impactor. Analyses were undertaken with the following accelerator-based methods: particle-induced X-ray emission (PIXE) and particle elastic scattering analysis (PESA). Data from 48 flights during 1 year are used, leading to a total of 106 individual comparisons. The ratios of the particle volume from the OPC and the total mass from the analyses were in $84 \%$ within a relatively narrow interval. Data points outside this interval are connected with inlet-related effects in clouds, large variability in aerosol composition, particle size distribution effects and some cases of non-ideal sampling. Overall, the comparison of these two CARIBIC measurements based on vastly different methods show good agreement, implying that the chemical and size information can be combined in studies of the MT/UT/LMS aerosol.
\end{abstract}

\section{Introduction}

The particles of the atmospheric aerosol have a broad spectrum of sources, where the anthropogenic contribution often can be difficult to quantify due to influences from natural sources at background conditions (Andreae and Rosenfeld, 2008). Despite being trace constituents of the atmosphere, particles are of considerable concern, such as adverse health effects and premature deaths (Pope III and Dockery, 2006) and climate change (IPCC, 2013), where in the latter case the direct and indirect effects of atmospheric particles can act as to mask the climate impact of greenhouse gases (Schwartz et al., 2010).

In this study the aerosol at $9-12 \mathrm{~km}$ altitude is investigated, thus dealing with the upper troposphere (UT) and the lowermost stratosphere (LMS) in the extratropics and the middle troposphere (MT) in the tropics. The vast majority of all studies of atmospheric aerosol concerns surface conditions. Aircraft measurements and remote sensing from the surface (Mattis et al., 2010) or from satellites, such as the NASA satellite CALIPSO (Vernier et al., 2011), are used to study the aerosol at higher altitudes. Besides information on scattered intensity for a given wavelength, multi-wavelength measurements combined with assumptions on particle composition and shape has been used to estimate particle size distribution in the 0.1 to above $1 \mu \mathrm{m}$ diameter range (Bauman et 
al., 2003). Smaller particles cannot be detected by remote sensing, and therefore also most of the aerosol dynamics cannot be studied. In addition, aerosol chemical information is normally not available by remote sensing except in very special circumstances (Rinsland et al., 1994). Remote sensing thus needs to be complemented by in situ observations of particle size distributions and composition in order to study sources and processes forming the aerosol. Research aircraft and balloons have been used for in situ studies of particle formation (de Reus et al., 1998), particle size distributions (Deshler et al., 2003) and particle chemical composition (Huebert et al., 2004). Based on the use of in-service passenger aircraft, long-term aerosol observations have been undertaken from the CARIBIC (Civil Aircraft for the Regular Investigation of the atmosphere Based on a Instrument Container) platform for the years 1997-2002 and 2005 to present (Brenninkmeijer et al., 1999, 2007) concerning particle chemical composition (Martinsson et al., 2001) and particle number concentrations (Hermann et al., 2003).

Aerosol particles in the $9-12 \mathrm{~km}$ altitude region contain a significant fraction of sulfurous aerosol (Dibb et al., 2000; Xu et al., 2001; Martinsson et al., 2001, 2005; Kojima et al., 2004). The carbonaceous fraction is another major component of the aerosol in this region (Murphy et al., 1998, 2006; Nguyen et al., 2008, Friberg et al., 2014). Black carbon constitutes a small fraction of the total carbon (Schwarz et al., 2010; Friberg et al., 2014). Occasionally chemical elements connected with crustal matter and fires are observed (Papaspiropoulos et al., 2002), which on rare occasions can have a strong influence on aerosol particle concentration (Eguchi et al., 2009; Dirksen et al., 2009; Fromm et al., 2010). Particles from explosive volcanism have strong effects on the studied region at times, affecting the climate (Ammann et al., 2003; Solomon et al., 2011), stratospheric ozone (McCormick et al., 1995) and aviation (Gislason et al., 2011). The aerosol particles in volcanic clouds contain besides the ash component (Schumann et al., 2011; Andersson et al., 2013) large sulphurous and carbonaceous components (Martinsson et al., 2009; Schmale et al., 2010; Carn et al., 2011).

The size distribution of the aerosol in the lowermost stratosphere is also strongly influenced by volcanism (Bauman et al., 2003). Hervig and Deshler (2002) compared balloonborne optical particle counter (OPC) measurements with satellite-based measurements of extinction for several wavelengths from SAGE II and HALOE and found good agreement during periods of strong volcanic influence, whereas the OPC registered considerably higher particle surface area than the satellites during periods with little volcanic influence.

The study presented here deals with two very different CARIBIC aerosol measurements. Particle volume is obtained by integrating the size distributions obtained from an OPC. Subsequently these results are compared with the aerosol mass from samples that were analysed with PIXE (particle-induced X-ray emission) and PESA (particle elastic scattering analysis) for concentrations of all major and several minor chemical elements. Together these different measurements can deepen our understanding of the atmospheric aerosol by this combination of chemical and physical information. However, to reach that goal an assessment of the degree of agreement between the two measurements is needed. Therefore this paper is devoted to the comparison of the total particle volume concentration obtained from the CARIBIC $\mathrm{OPC}$ and the total mass concentration obtained from the analyses of the CARIBIC aerosol samples.

\section{Methods}

The measurements presented here were undertaken from the CARIBIC observatory (Brenninkmeijer et al., 2007; www. caribic-atmospheric.com/) where a large number of trace gases are measured and aerosol particles are characterized with respect to size distribution and composition during monthly sets of usually four intercontinental flights at 9$12 \mathrm{~km}$ altitude. The CARIBIC system comprises an instrumented container that is connected to a multiple probe inlet system for trace gases and aerosol that is permanently mounted on the belly of a Lufthansa Airbus A340-600. Concentrations of $\mathrm{CO}, \mathrm{O}_{3}, \mathrm{NO} / \mathrm{NO}_{\mathrm{y}}, \mathrm{VOCs}$, gaseous and condensed water are determined, and air samples collected are analysed for greenhouse gases, hydro and halo carbons (Brenninkmeijer et al., 2007; Schuck et al., 2009; Baker et al., 2010; Oram et al., 2012). Aerosol particle number concentration measurements down to a diameter of $4 \mathrm{~nm}$ are undertaken with three condensation particle counters (CPC, TSI model 7610; Hermann et al., 2003), and for the particle size distribution in the diameter range $\sim 130-\sim 1000 \mathrm{~nm}$ a 16 channel OPC (RION, KS-93) is used (Rauthe-Schöch et al., 2012). Furthermore, aerosol samples are collected for subsequent analysis with respect to all major and several minor constituents (Martinsson et al., 2001; Nguyen et al., 2006; Nguyen and Martinsson, 2007). Details of the inlet system are described by Brenninkmeijer et al. (2007). The efficiency of the aerosol inlet is estimated to be $60 \%$ for $5 \mu \mathrm{m}$ diameter particles (Rauthe-Schöch et al., 2012). Based on modelling and previous experience the efficiency of the inlet is estimated to exceed $90 \%$ for particles in the size range 0.01 $1 \mu \mathrm{m}$ diameter.

This comparison of the CARIBIC OPC and the analytical results obtained from the aerosol sampler span 1 year from April 2011 to March 2012. The measurements were undertaken during flights from Frankfurt in Germany to northern South America (24 flights), western North America (14), the Indian subcontinent (8) and eastern Asia (2), thus spanning a large region from $120^{\circ} \mathrm{W}$ to $120^{\circ} \mathrm{E}$ and 10 to $75^{\circ} \mathrm{N}$. The average flight altitude was $10900 \mathrm{~m}$ with a span of 9500 to $11900 \mathrm{~m}$. For those samples collected in clouds the average air temperature was below $230 \mathrm{~K}$, implying that the 
clouds were dominated of ice particles (Koop et al., 2000; Rosenfeld and Woodley, 2000). The meteorological modelling along the CARIBIC flight paths indicates that each sample affected by clouds encountered hydrometeors that in most cases consisted to $100 \%$ of ice, the lowest fraction of ice being $99 \%$ (http://www.knmi.nl/samenw/campaign support/CARIBIC/). This is consistent with measured temperatures.

The aerosol sampling requires the longest sampling time of the two methods, thereby determining the amount of data available. For the investigated period of 1 year, 153 aerosol samples are available. This number available for comparison is lower by constraints that, of course, OPC data should be available and that uncertainties in total mass due to detection limit should be within $\pm 5 \%$ (described below). In addition, clouds were found to seriously affect the comparison. Therefore also measurements of gaseous and total water concentrations should be available for identification of samples collected in cloudy conditions. These requirements together reduce the number of samples available for the comparison to 106. The OPC - aerosol sampler intercomparison primarily deals with the integrated particle volume concentration obtained from the OPC $\left(C_{\mathrm{V}}\right)$ and the total aerosol mass concentration obtained as the sum of all major and several minor constituents of the aerosol samples $\left(C_{\mathrm{m}}\right)$.

\subsection{Aerosol sampling and analysis}

CARIBIC aerosol samples are collected by impaction on a $0.2 \mu \mathrm{m}$ polyimide film, Proline-10, from Moxtek Inc., Orem, Utah, USA. The sampling unit contains three kinds of nozzles. Here nozzles connected the 14 channels that were sequentially activated for sampling and subsequent PIXE/PESA (Particle-Induced X-ray Emission/Particle Elastic Scattering Analysis) analysis were used. The typical sampling time for each sequential sample is $100 \mathrm{~min}$. The collection efficiency of the sampler is $97 \% \pm 4 \%$ for particles with aerodynamic diameter larger than $0.2 \mu \mathrm{m}$, and the $50 \%$ cut-off diameter is $0.08 \mu \mathrm{m}$ (Nguyen et al., 2006).

A cyclone separator placed up-stream of the sampler limits the upper particle size to $2 \mu \mathrm{m}$ aerodynamic diameter. The penetration of the cyclone by particles smaller than $1 \mu \mathrm{m}$ diameter has been measured to be $100 \% \pm 3 \%$ (Nguyen et al., 2006). This cyclone is used exclusively for the aerosol sampler, implying that the OPC, to be described below, does not have the same definition of the upper size limit.

The collected samples were analysed for elemental composition by ion beam analysis (IBA). For sulphur (S) and elements with larger atomic number PIXE is used (Johansson and Campbell, 1988). The lower limit of the PIXE analysis of this study with respect to atomic number is connected with spectral interference, see Andersson et al. (2013) for further details. Hydrogen $(\mathrm{H})$, carbon $(\mathrm{C})$, nitrogen $(\mathrm{N})$ and oxygen (O) are analysed by PESA. The analytical setup has been optimised with respect to sampling substrate and analytical parameters for PIXE (Papaspiropoulos et al., 1999) and PESA (Nguyen and Martinsson, 2007). During the time period of this study the detection efficiencies (i.e. the fraction of the samples where the element was detected) for $\mathrm{H}, \mathrm{C}, \mathrm{N}$, $\mathrm{O}$ and $\mathrm{S}$ were 100, 96, 82, 95 and $100 \%$. Minor constituents were detected less frequently, like for instance potassium $(\mathrm{K})$ $41 \%$, iron $(\mathrm{Fe}) 44 \%$ and nickel $(\mathrm{Ni}) 30 \%$. The accuracy of the analyses is estimated to $10 \%$ (Papaspiropoulos et al., 2002; Nguyen and Martinsson, 2007).

The total aerosol mass concentration (in $\mathrm{ng} \mathrm{m}^{-3} \mathrm{STP}$; standard temperature and pressure) was obtained as the sum of all elemental mass concentrations. An element that was not detected in a sample was represented by the half of its minimum detection limit (MDL) which was added to the sum of the elements. When more than $5 \%$ of that sum was from undetected elements (represented by half the MDL) the measurement was discarded, implying that the total mass concentration given has a $\pm 5 \%$ uncertainty due to elemental concentrations below the MDL. This requirement implied that only samples with detection of all the five major elements, $\mathrm{H}, \mathrm{C}, \mathrm{N}, \mathrm{O}$ and $\mathrm{S}$, were selected for this analysis. Uncertainties slightly larger than $5 \%$ could appear for samples with a significant crustal component because some of the crustal elements, most notable silicon, are not analysed with adequate detection limits. This could lead to an underestimation of the crustal component by approximately $41 \%$ according to average crust composition (Weaver and Tarney, 1984). For the two samples with the largest mass fractions of crust, containing 22 and $13 \%$, respectively, the total mass concentration could thus be underestimated by 9 and $5 \%$, respectively.

Combining the uncertainties of the sampling efficiency (4 and $3 \%)$, elemental analysis (10\%) and effects from the minimum detection limit (5\%) the combined uncertainty of the mass concentration obtained from sampling and analysis becomes $12 \%$.

The aerosol sampler has demonstrated excellent properties in calibration procedures (Nguyen et al., 2006). Calibration results were obtained using liquid aerosol consisting of dioctyl serbacate (DOS) with traces of uranine. The performance of impactors is, however, sensitive to particle material as well as the amount of mass deposited. Solid particles can bounce off the sampling substrate, and in that way be lost. Bounce-off can be counteracted by the use of a coating of the impaction surface. Pak et al. (1992) showed that a coating of Apiezon- $\mathrm{L}$ grease needs to be more than $9 \mu \mathrm{m}$ thick to obtain close to $100 \%$ impactor collection efficiency for solid particles, whereas silicon oil shows more promising properties with rather high efficiency at $0.3 \mu \mathrm{m}$ thickness. However, applying such a thickness would result in a factor of 2.5 thicker sampling substrate causing typically a factor 1.6 worse PIXE detection limits (if contamination in the coating process can be avoided). The effect on carbon detection can be expected to be much stronger, because the coating thickness variance will be added to that of the polyimide film which is low (Nguyen and Martinsson, 2007). Given the usually low 
UT/LMS aerosol concentrations and the short sampling time, minimum detections limits are very important. Therefore no coating of the impaction surface was used. This should not be seen as a general recommendation, but rather as an adaption to a special measurement situation with respect to required detection limits and properties of MT/UT/LMS particles. Overloaded impactor substrates could suffer blow-off, where a sizable fraction of a solid or semi-solid deposit is blown away from the impaction zone. Impactors overloaded with liquid particles may wet the surface of the sampling substrate, causing a drift of deposited material away from the impaction region. Mass deposited away from this region might be outside the area where the analytical beam impinges on the sample. That mass will not interact with the beam thus causing too low measured concentrations.

In order to study the influence from the distorting effects on the aerosol samples of this study, all the 106 samples were photographed using a Canon EOS 550D with an EFS $15-85 \mathrm{~mm}$ lens. A photodiode placed behind the sample was used for illumination. The images were systematically evaluated based on the appearance of the deposit. Evidence of bounce-off could be found for one group of samples. Liquid samples wetting the surface outside the impaction region could also be observed, whereas no signs of large features at the outer part of the sample indicative of blow-off were obtained from any of the samples. Each of the four orifices of the impactor nozzle should produce a deposit, thus causing a square pattern of four deposits with a distance of $0.9 \mathrm{~mm}$ to the centre of the sampling substrate. The samples were classified in four basic groups. The first group, type 1, contains samples with no deviation from the ideal appearance, see Fig. 1a. Some samples contain low amounts of deposited mass, making identification of secondary deposition pattern more difficult. Type 1 samples are subdivided in normal (type 1.1) and low-loaded (1.2) samples. Frequently thin filaments of deposit stretching outside the regular impaction area were found (type 2, Fig. 1b). The type 2 samples are subdivided according to (2.1) wetting only inside the analytical beam area, (2.2) minor wetting outside the beam area and (2.3) considerable wetting outside the beam area. When the impactor jet meets the sampling surface the air flows out over the surface in all directions. Because of the fact that the present impactor contains four jets this outflow causes an interaction between the jets, causing secondary deposition of bounce-off-particles in between the ordinary deposition area. This is manifested by a deposition spot in the centre (Fig. 1c). In some cases a cross can be discerned, marking the outflow path of air from the central area. These type 3 samples were subdivided into three categories: (3.1) central spot discerned, (3.2) cross discerned and (3.3) cross clearly visible, in expected order of increasing severity of the bounceoff problem observed. Several images reveal tiny spots outside the central deposition area. This could be caused by imperfection of the polyimide film or it could be single particles that have bounced. A few samples have a large number

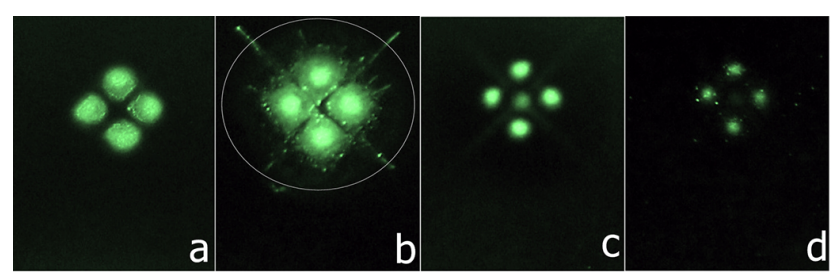

Figure 1. Photographic images of aerosol deposits from the CARIBIC aerosol sampler, where particles are collected from four impactor orifices. (a) Type 1: four spots of deposit (detected mass $100 \mathrm{ng}$ ). (b) Type 2: thin filaments of liquid aerosol out from the main deposit $(670 \mathrm{ng})$. (c) Type 3 : four spots and a secondary deposition pattern $(92 \mathrm{ng})$. (d) Type 4: several small spots outside the deposition area (32 ng). The ellipse in (b) illustrates the beam size which is $5.5 \mathrm{~mm}$ vertically and $5.5 / \cos \left(23^{\circ}\right)$ horizontally.

of tiny spots outside the regular deposition area. When the number of spots over the $16 \mathrm{~mm}$ diameter polyimide film exceeded 15 , the samples were classified as type 4 . Otherwise they were classified according to the appearance of central deposit. An example of these type 4 samples is shown in Fig. 1d.

The different deposition types were summarized by a qualitative indicator (QI) expressing qualitatively the problem with losses for each sample based on the deposition pattern. $\mathrm{QI}=0$ are the samples where no significant losses are expected. The deposit types with $\mathrm{QI}=0$ are $1.1,1.2,2.1$ and 2.2. Samples indicating discernible losses $(\mathrm{QI}=1)$ comprise only type 3.1 samples. Sample deposits indicating more serious losses $(\mathrm{QI}=2)$ include deposit types 2.3, 3.2, 3.3 and 4. Classification in these main and sub categories will be used in the evaluation of the comparison between the sampler and OPC.

To further substantiate the findings from images of the samples, use will be made of results from the elemental analysis itself. All samples are analysed in two steps, the first with a large ion beam area $(5.5 \mathrm{~mm}$ diameter with beam current $150 \mathrm{nA}$ and duration of $200 \mathrm{~s}$ per sample) used only for quantitative PIXE analysis. The second method, used for relative PIXE and PESA analyses, is based on a small beam ( $1 \mathrm{~mm}$ diameter). This small-beam analysis is based on three irradiations (beam current $15 \mathrm{nA}$ with duration $3 \times 200 \mathrm{~s}$ per sample), one over the aerosol deposit and two blank irradiations outside the main deposit area of the impactor at $4 \mathrm{~mm}$ distance from the deposit centre at opposite sides (Nguyen and Martinsson, 2007). These two internal blank measurements can be utilized to obtain an estimate of aerosol deposit outside the $5.5 \mathrm{~mm}$ diameter beam of the quantitative PIXE analysis. They should represent an area from the outer bound of the large beam to an outer bound where half of this doughnut area is inside a $4 \mathrm{~mm}$ radius. A circle with $4 \mathrm{~mm}$ radius has approximately twice the area of the beam in the slightly tilted sample plane $\left(23^{\circ}\right)$. Adding the same surface area outside the $4 \mathrm{~mm}$ radius, the blank spots can be 
seen as to represent an area twice the size of the large beam, between diameters 5.5 and $9.5 \mathrm{~mm}$. The estimated mass deposited is the areal density of an element (in $\mathrm{ng} \mathrm{cm}^{-2}$ ) multiplied with the surface area. To estimate non-ideal deposition outside the primary impactor deposition area the ratio between the mass deposited between 5.5 and $9.5 \mathrm{~mm}$ diameter $\left(m_{\text {udet }}\right)$ and the mass detected in the quantitative analysis within $5.5 \mathrm{~mm}$ diameter $\left(m_{\mathrm{det}}\right)$ is formed. This ratio can only be formed for elements detected with PIXE because of the strong signal of $\mathrm{H}, \mathrm{C}, \mathrm{N}$ and $\mathrm{O}$ from the polyimide sampling substrate. The major aerosol constituent sulphur is detected with PIXE, and will therefore serve as the element used for estimation of deposition outside the main deposition area of the impactor. From Fig. 1c it is clear that secondary deposition is inhomogeneous in the vicinity of the impactor jets. It is not clear to what degree the secondary deposition pattern reaches outside the irradiated area of the sample. Therefore the $m_{\mathrm{udet}} / m_{\mathrm{det}}$ ratios should be treated with some caution, especially for sample types 3.2 and 3.3. Additionally, this ratio only describes the aerosol components internally mixed with the sulphate aerosol. Components of other size modes, like crustal particles, may behave differently, as will be shown in Sect. 3.1. Samples with QI=0, i.e. samples showing no visible imperfections in the deposition pattern, have $m_{\mathrm{udet}} / m_{\mathrm{det}}$ ratios narrowly distributed around 0.03 indicating that $3 \%$ of the aerosol deposit was outside the $5.5 \mathrm{~mm}$ ion beam used in the quantitative PIXE analysis. All samples were therefore corrected by that percentage to account for regular deposition outside the analysed area.

The analyses of the aerosol samples are undertaken in high vacuum of approximately $10^{-5} \mathrm{hPa}$. The samples remain at this pressure for $6 \mathrm{~h}$, the duration of both analytical steps for a batch of 21 samples. This will cause losses of chemical compounds with a vapour pressure larger than the order of $10^{-7} \mathrm{~Pa}$ at room temperature (Martinsson, 1987; Deiters and Randzio, 2007). The main aerosol components observed in the analysed UT/LMS samples over the years are sulphurous and carbonaceous components, but sometimes also a significant crustal component can be observed. The sulphate compounds common in the atmosphere are not lost during analysis when particles, like in this study, are deposited onto a thin substrate, unless an external heating source is used (Martinsson and Hansson, 1988; Mentes et al., 2000). Among other common inorganic salts of the atmospheric aerosol, sodium chloride is stable during analysis, whereas ammonium nitrate will evaporate, if present. The occasional crustal component is expected to remain in the sample during analysis. The atmospheric carbonaceous aerosol component contains a broad range of vapour pressures. Therefore a definition of what is analysed is of need (Martinsson, 1987). In this case the IBA analytical definition most likely deviates from that during the OPC measurements, implying that the amount of carbonaceous aerosol determined by IBA could be smaller than the amount present during the OPC measurements.

\subsection{Optical particle counter}

For CARIBIC, a KS-93 OPC (RION CO., Ltd., Japan) was modified and applied for the first time onboard aircraft. The KS-93 has a diode laser with $830 \mathrm{~nm}$ wavelength, a lower detection limit of about $120 \mathrm{~nm}$ particle diameter, a robust synthetic quartz optical cell and is relatively small in size $(135 \times 280 \times 150 \mathrm{~mm})$, which makes it all well suited for airborne atmospheric research. The modified OPC is mounted together with the flow control system and the data acquisition in a $19^{\prime \prime}$ rack unit. For data analysis the signals of the three OPC internal amplifiers are recorded with a real-time data acquisition system (PXI, National Instruments, USA) with $3 \mu$ s resolution. As the signal of one particle has an average duration of about 60 to $90 \mu \mathrm{s}$, each pulse is resolved with 20 to 30 data points. This data acquisition allows a free choice of the sampling time and number of channels. For the present analysis particle pulse heights were sorted into 16 channels and averaged over $300 \mathrm{~s}$. For CARIBIC, the KS-93 signal output is improved by applying particle free sheath air $\left(0.135 \mathrm{~L} \mathrm{~min}^{-1}\right)$ around the aerosol sampling air $\left(0.015 \mathrm{~L} \mathrm{~min}^{-1}\right)$. In this configuration the CARIBIC OPC yields reliable data for particles larger than about $130 \mathrm{~nm}$ (optical diameter). The largest particle diameter which can be size-resolved is between 1.0 and $1.3 \mu \mathrm{m}$ and depends on the particle refractive index and the respective calibration curve. However, as can be seen in Fig. 8, most of the volume distributions in the UT/LMS have their maximum in the particle size range between 300 and $600 \mathrm{~nm}$. Hence the analysis in this study does not strongly depend on the OPC upper particle diameter limit. For the present analysis a theoretical response function based on spherical particles and the Mie theory was used (van de Hulst, 1981; Bohren and Huffman, 1983). This curve was related to the signal output by calibrating the OPC with latex and ammonium sulfate particles in the laboratory. Note that the OPC also counts particles larger than the upper size limit, but cannot determine their exact size. These particles are assigned to the largest particle size channel, which is therefore biased and not used in the analysis here. Uncertainties of the OPC data evaluation originate mainly from the "unknown", hence to be estimated particle refractive index, and the accuracy of the sampling air flow. They amount to $\sim 10 \%$ in particle size and $\sim 19 \%$ for the particle number concentration. Due to the cubed dependence of the particle volume on diameter the combined uncertainty of $C_{\mathrm{V}}$ becomes $50 \%$. For CARIBIC, the refractive index was calculated using literature values of the UT particle chemical composition $\left(44 \% \mathrm{H}_{2} \mathrm{SO}_{4}, 44 \%,\left(\mathrm{NH}_{4}\right)_{2} \mathrm{SO}_{4}, 10 \%\right.$ organic carbon and $2 \%$ soot) and a mixing rule to $1.479-0.0143 i$. This refractive index was applied for the whole OPC size range. Additional information of the OPC unit is given in Rauthe-Schöch et al. (2012). 


\subsection{Additional methods}

Besides the data from the OPC and the aerosol sampler, measurements of water are used to identify measurements that were influenced by clouds. The CARIBIC inlet system houses a forward-facing inlet tube for total water $\left(\mathrm{H}_{2} \mathrm{O}_{\text {tot }}\right.$; being the sum of cloud water/ice and gaseous water) and one sideways-facing inlet tube for gaseous water $\left(\mathrm{H}_{2} \mathrm{O}_{\text {gas }}\right)$ only. These two inlet lines are connected with two water vapour sensors, a chilled mirror frost point hygrometer (FPH) measuring total water (time resolution 10-180 s) and a twochannel photoacoustic laser spectrometer (PAS) detecting $\mathrm{H}_{2} \mathrm{O}_{\text {tot }}$ and $\mathrm{H}_{2} \mathrm{O}_{\text {gas }}$ (time resolution: $\sim 5 \mathrm{~s}$ ). The PAS data are calibrated post-flight using the FPH data showing a total uncertainty of approximately $0.5 \mathrm{~K}$ (verified by regular laboratory-based cross-checks to high precision FHP instrument MWB LX-373). The calibrated PAS data have a precision of $2 \%$ or $0.5 \mathrm{ppmv}$ (whichever is higher).

We use the dynamical tropopause to differentiate between tropospheric and stratospheric air. This tropopause is based on the strong gradient in potential vorticity (PV) in the tropopause region (Hoerling et al., 1991; Hoinka, 1997). The PV along the flight track was obtained from archived European Centre for Medium-Range Weather Forecasts (ECMWF) analyses with a resolution of $1 \times 1$ degree in the horizontal and at 91 vertical hybrid sigmapressure model levels. The PV was interpolated linearly in longitude, latitude, log pressure and time to the position of the aircraft. Based on PV, air masses were classified as tropospheric for average $\mathrm{PV}<1.5 \mathrm{PVU}$ (potential vorticity units; $1 \mathrm{PVU}=10^{-6} \mathrm{~K} \mathrm{~m}^{2} \mathrm{~kg}^{-1} \mathrm{~s}^{-1}$ ), and as belonging to the tropopause region for $1.5<\mathrm{PV}<3 \mathrm{PVU}$. The samples taken in the LMS are subdivided in three groups of varying depth into the LMS, 3-5 PVU, 5-7 PVU and measurements taken in air masses with PV $>7$ PVU.

\section{Results and discussion}

The primary measure used in the comparison between the OPC and the aerosol samples is the ratio of the OPC particle volume concentration $\left(C_{\mathrm{V}}\right)$ to the total mass concentration $\left(C_{\mathrm{m}}\right)$ obtained as the sum of the elemental concentrations from PIXE and PESA analysis of the aerosol samples. Figure 2 shows the 1 year data used to evaluate the relative performance of the two methods that are based on completely different physical principles. From the distribution it is clear that a large fraction of the measurements $(85 \%)$ have $C_{\mathrm{V}} / C_{\mathrm{m}}$ ratios from 0.55 to $1.55 \mathrm{~cm}^{3} \mathrm{~g}^{-1}$. Out of the 106 samples 14 were found to have $C_{\mathrm{V}} / C_{\mathrm{m}}$ ratios larger than the $1.55 \mathrm{~cm}^{3} \mathrm{~g}^{-1}$ upper limit of this range and three were below the lower limit. The causes contributing to these 17 outliers will be investigated next.

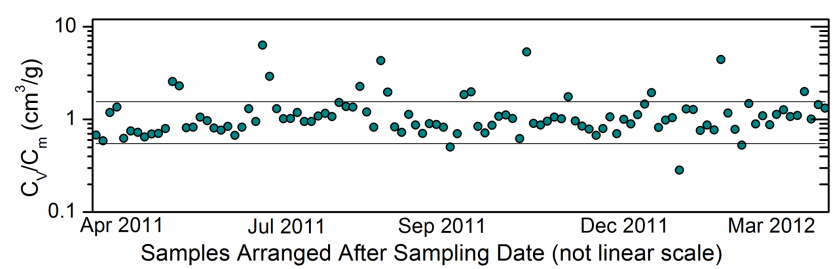

Figure 2. One year time series from CARIBIC measurements of the ratio of aerosol elemental concentrations from samples analysed with PIXE and PESA $\left(C_{\mathrm{m}}\right)$ and particle volume concentrations obtained from the OPC $\left(C_{\mathrm{V}}\right)$.

\subsection{Examination of outlying data points}

To shed light on the causes of outlying $C_{\mathrm{V}} / C_{\mathrm{m}}$ ratios, the measurement situation, elemental composition features, size distribution and aerosol sample deposit patterns will be scrutinized. First the special case of sampling in clouds will be studied. Based on the CARIBIC measurements of gaseous and total water mixing ratios, intercepted clouds are detected (Brenninkmeijer et al., 2007). Figure 3 a shows the $C_{\mathrm{V}} / C_{\mathrm{m}}$ ratio related to the cloud ice concentration. Approximately half of the samples were obtained without any contact with clouds. The degree of cloud contact of the other samples varies strongly (note the logarithmic scale). When the cloud ice concentration is high, several measurements show high $C_{\mathrm{V}} / C_{\mathrm{m}}$ ratio. The aerosol inlet is designed to collect particles of a few micrometre in diameter or smaller. When the inlet approaches particles at a cruise speed of $230 \mathrm{~m} \mathrm{~s}^{-1}$, large particles that hit the leading edge of the shroud or, less likely the inlet cone itself, can disintegrate adding artifactual particles to the sampling airstream (Korolev et al., 2011). Because the leading edges and rim of the CARIBIC inlet have a surface-coating of nickel, we evaluated the connection between nickel elemental concentration and cloud ice concentrations. Figure $3 \mathrm{~b}$ demonstrates a strong correlation for cloud ice concentration above $5 \mathrm{ppmv}$ with aerosol sample nickel mass fractions larger than $0.05 \%$, indeed showing that, besides break-up of ice particles, the inlet contributes nickel when measuring inside clouds. This group of $10 \mathrm{sam}-$ ples will be further investigated, starting with photographic images of the aerosol samples to inspect the deposition patterns of the samples.

Out of this group of 10 instances four occurred in the tropics, five in the extra-tropical UT and one in the tropopause region. Figure 4a contains indeed a very incoherent message on the connection between deposition pattern and cloud influence or $C_{\mathrm{V}} / C_{\mathrm{m}}$ ratio. Four of the samples show clear signs of losses based on a non-ideal deposition pattern $(\mathrm{QI}=2$; one type 3.2 and three type 4), four show traces of secondary deposition and the remaining two samples are classified as $\mathrm{QI}=0$ samples. The two samples most affected by clouds, sample No. 1 and 2, have deposition pattern type 4. They also have the two highest $C_{\mathrm{V}} / C_{\mathrm{m}}$ ratios. The type 4 samples 


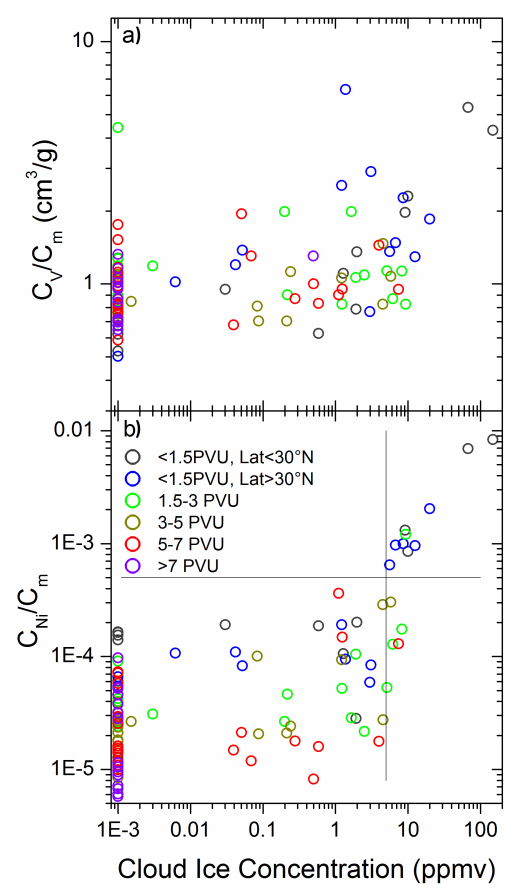

Figure 3. (a) Dependence of the ratio of particle volume to mass concentrations from OPC and IBA measurements $\left(C_{\mathrm{V}} / C_{\mathrm{m}}\right)$, respectively, on average cloud ice concentration during each sampling period. (b) The latter related to the mass fraction of nickel in the samples. Note, in order to display zero cloud ice concentration in the logarithmic scale, $10^{-3}$ ppmv was added to each data point.

are, as will be shown later, rather unusual, suggesting that the artefact particles generated at the inlet have a high probability for bounce-off and become spread over the surface. The volume size distributions of Fig. $4 \mathrm{~b}$ are typical of artefactual particles due to particle break-up in clouds and do not appear in the absence of clouds. High values of the $C_{\mathrm{V}} / C_{\mathrm{m}}$ ratio (Fig. 4c) are connected with high concentrations of large particles. It is also clear that there is a strong correlation between nickel in the aerosol samples and cloud ice concentration (Fig. 3b) likely originating in collisions between ice particles and materials of the walls of the inlet (Murphy et al., 2004). However, the amount of nickel collected in the sampler is much less than the signal registered in the OPC channels for large particles. Bounce-off could cause reduced collection efficiency of these newly formed, solid particles in the aerosol sampler. Another difficulty arises from the fact that the OPC measurements are based on the assumption of a sulphate-dominated aerosol, thus causing large sizing uncertainties for nickel particles due to the use of inadequate refractive index in the data evaluation. Additionally, nickel has a large density $\left(8.9 \mathrm{~g} \mathrm{~cm}^{-3}\right)$ implying that the cyclone in front of the sampler catches particles approximately a factor of 3 smaller in terms of geometrical diameter compared to $2 \mu \mathrm{m}$ aerodynamic diameter cut-off. Hence it is likely that a large fraction of the particles registered by the OPC is
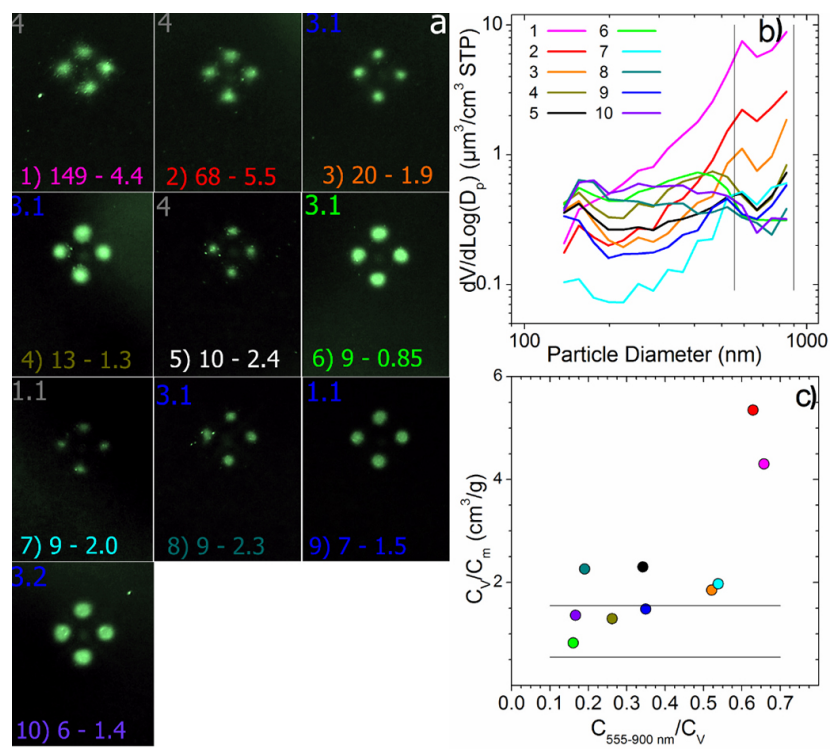

Figure 4. (a) Aerosol deposition pattern for samples affected by ice clouds. Numbers on bottom of pictures are measurement number, cloud ice concentration (ppmv) and OPC volume to IBA mass concentration ratio $\left(C_{\mathrm{V}} / C_{\mathrm{m}} ; \mathrm{cm}^{3} \mathrm{~g}^{-1}\right)$. The numbers in the top left corners show the aerosol deposit classification and their colour indicates air mass type according to the legend of Fig. 3. (b) Particle volume size distribution for measurements affected by clouds. Numbers in legends are measurement numbers in (a). (c) $C_{\mathrm{V}} / C_{\mathrm{m}}$ related to particle volume fraction in the four OPC channels of the largest sizes $(555-900 \mathrm{~nm})$. The colour of distributions in (b) and markers in (c) corresponds to bottom text colours in (a).

outside the range of the sampler, thus further adding to the uncertainties. It is clear that the large diameter channels of the CARIBIC OPC are severely affected by clouds, as are the CARIBIC nickel concentration measurements from the aerosol samples.

Measurements where the crustal component is significant were identified from the iron concentration and its relative concentration to potassium, calcium and titanium. Six samples have a relative iron concentration $\left(C_{\mathrm{Fe}} / C_{\mathrm{m}}\right)$ larger than $0.3 \%$, corresponding to a crustal fraction $\left(C_{\text {crust }} / C_{\mathrm{m}}\right)$ of approximately $6 \%$ according to average crust composition (Weaver and Tarney, 1984). The deposition patterns of crustcontaining samples (Fig. 5a and, for sample No. 1, Fig. 4a) all show signs of losses. Five of the samples have $\mathrm{QI}=2$ and the remaining sample $\mathrm{QI}=1$. The $C_{\mathrm{V}} / C_{\mathrm{m}}$ ratio is connected with the deposition pattern to a higher degree than the cloud-influenced samples. The size distributions of measurements with a strong crustal component are shown in Fig. 5b. The size distribution of the cloud-affected measurement (No. 1) differs markedly from the other crust-influenced measurements with high concentrations of the largest particles artificially produced in the inlet. Yet, all but sample No. 12 show high concentration in the OPC channel for the largest particles. Crustal particles usually are larger than 

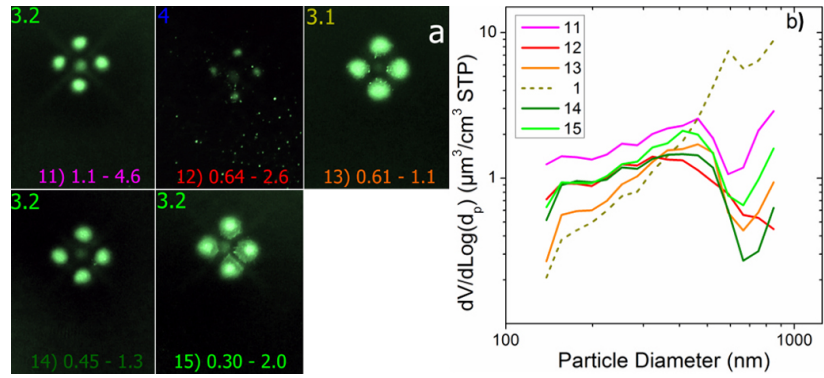

Figure 5. (a) Particle deposition patterns on the aerosol samples with a strong crustal component. Sample No., $C_{\mathrm{Fe}} / C_{\mathrm{m}}$ mass ratio (\%) and $C_{\mathrm{V}} / C_{\mathrm{m}}\left(\mathrm{cm}^{3} \mathrm{~g}^{-1}\right)$ are shown in the bottom of the images. Numbers in top left corners show deposition pattern and the colour indicates air mass type according to the legend of Fig. 3. (b) Volume size distributions from the OPC for samples with an $\mathrm{Fe}$ fraction larger than $0.3 \%$ of the particle mass. Sample 1 (dashed) is also affected by clouds.

sulphurous/carbonaceous particles indicating that the crustal particles mainly appear in the OPC channels for the largest particle sizes. Crustal particles differ significantly from the sulphate OPC calibration substance in refractive index as well as in particle shape, implying that the uncertainty of the OPC sizing of the crustal particles is large. The density of crustal particles is comparatively high, usually around $2.7 \mathrm{~g} \mathrm{~cm}^{-3}$. This increases the probability that particles in the upper channels of the OPC are outside the upper aerodynamic limit of the aerosol sampler. The balance of these circumstances indicates that a mismatch in particle size range of the OPC and the aerosol sampler contributes to the high $C_{\mathrm{V}} / C_{\mathrm{m}}$ ratios as well as non-ideal collection of crustal particles demonstrated by the deposition patterns.

The ratio of carbon (C) to sulphur (S) mass concentration varies by a factor of more than 100 between the samples in this study. Such variability in composition will of course affect the refractive index of the particles. Here samples with mass concentration ratio $\mathrm{C} / \mathrm{S}>5$ will be examined. The mass of sulphate aerosol composed $\mathrm{H}_{2} \mathrm{SO}_{4}-\left(\mathrm{NH}_{4}\right)_{2} \mathrm{SO}_{4}$ can be estimated to be 4 times the mass of $\mathrm{S}$, implying that the carbonaceous component in these samples most likely is larger than the sulphurous fraction. Six of the 106 samples in this study had $\mathrm{C} / \mathrm{S}$ mass concentration ratios larger than 5. Three of these samples were affected by clouds and one contained crust, which strongly affect the results of the comparison between the OPC and the sampler. The remaining two samples (Fig. 6a) show rather faint deposition patterns, the deposit of sample No. 16 being barely visible. Both of them are classified as type 1.2. These two measurements differ markedly from the cloud-affected and crust-containing samples with respect to size distribution (Fig. 6b) by showing a mode of small particles (most clear for sample 16). This indicates that a fraction of the particles escapes detection in the OPC while collected by the sampler having a much lower
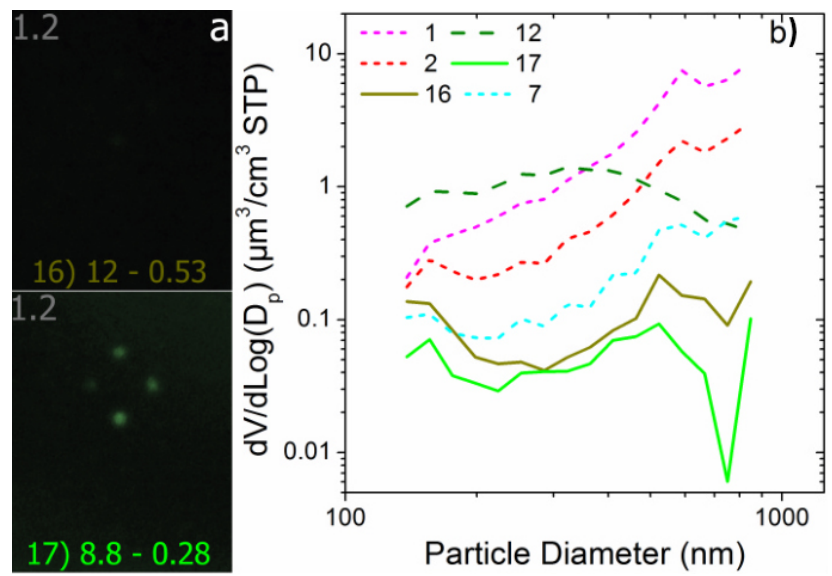

Figure 6. (a) Particle deposition patterns on the aerosol samples with a strong carbonaceous component. Sample No., C/S mass ratio and $C_{\mathrm{V}} / C_{\mathrm{m}}\left(\mathrm{cm}^{3} \mathrm{~g}^{-1}\right)$ are shown in the bottom of the images. Numbers in top left corners show deposition pattern and the colour indicates air mass type according to the legend of Fig. 3. (b) Volume size distributions from the OPC for samples with $\mathrm{C} / \mathrm{S}$ mass ratio larger than 5 . Samples also affected by clouds (short dashed in b) $[$ No. $1(\mathrm{C} / \mathrm{S}=32), 2(12)$ and $7(6.2)]$, as well as those affected by crust (dashed) [No. 12 (9.5)], are shown only in (b). Images of deposition patterns for these samples are displayed in Figs. 4 and 5, respectively.

cut-off. This could be the cause of low $C_{\mathrm{V}} / C_{\mathrm{m}}$ ratios. Also deviations of the actual optical properties from the refractive index assumed in the size attribution could be significant for these carbon-rich particles, e.g. underestimation of the soot fraction would lead to underestimation of $C_{\mathrm{V}}$.

After the examination of the influence from clouds, crust and $\mathrm{C} / \mathrm{S}$ composition 11 of the 17 outliers with respect to $C_{\mathrm{V}} / C_{\mathrm{m}}$ ratio have been identified. The remaining six outliers are shown in Fig. 7. It is clear that the sampling failed to produce quantitative collection for samples 18-20 (Fig. 7a). The remaining measurements (No. 21, 22 and 23) show good sampling characteristics. The size distribution of sample 23, (Fig. 7b) indicates that a significant fraction of the particle volume can be found on particles smaller than the lowest size channel of the OPC, thus causing a low $C_{\mathrm{V}} / C_{\mathrm{m}}$ ratio. The other two measurements (21 and 22) were taken in the LMS and display unusually large particles. This point will be discussed further in the next section.

\subsection{Problems connected with the size distributions}

To further evaluate the relation between the measurements with the OPC and the aerosol sampler, the size distributions will be examined. Difference in size range between the OPC (measuring 130-900 nm optical diameter) and the sampler (80-2000 $\mathrm{nm}$ aerodynamical diameter) could cause mismatch between the measurements, as discussed above. Assuming that the OPC measurements approximately resemble 

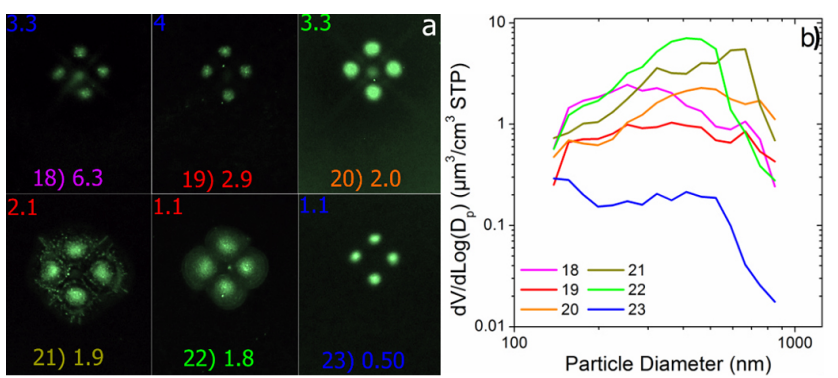

Figure 7. Samples outside the $C_{\mathrm{V}} / C_{\mathrm{m}}$ range of $0.55-$ $1.55 \mathrm{~cm}^{3} \mathrm{~g}^{-1}$ marked in Fig. 2 that cannot be connected with cloud, crust or large carbonaceous fraction. (a) Particle deposition patterns on the aerosol samples with measurement No. and $C_{\mathrm{V}} / C_{\mathrm{m}}$ $\left(\mathrm{cm}^{3} \mathrm{~g}^{-1}\right)$ at bottom of the images. Numbers in top left corners show deposition pattern and the colour indicates air mass type according to the legend of Fig. 3. (b) Volume size distributions from the OPC.

the geometrical diameter the measurements would have the same upper size limit for particles of density of $5 \mathrm{~g} \mathrm{~cm}^{-3}$. A lower density, usually true for atmospheric aerosol particles, would move the upper OPC limit downwards in aerodynamical size. In Fig. 8 particle volume size distributions are shown for all measurements not shown in Sect. 3.1 arranged according to the measurement region, i.e. UT, MT and LMS. It is clear that almost all measurements indicate that the particle volume outside the upper size limit of the OPC is small, implying that problems with mismatching upper size limits usually are small outside clouds (Fig. 4a) and in measurements with a strong crustal component (Fig. 5b).

The lower limits in particle size of the OPC and the impactor coincide at a particle density of approximately $0.4 \mathrm{~g} \mathrm{~cm}^{-3}$. This low value implies that size distributions with large volume in the channel for the smallest particles might be underrepresented in terms of total particle volume from the OPC. Some size distributions show high concentrations in the two smallest particle channels without having a dominant mode of larger particles. These distributions could be expected to be most affected in the $C_{\mathrm{V}} / C_{\mathrm{m}}$ ratio by particle volume outside the lower OPC measurement limit. In the tropics three measurements were taken in the fresh volcanic cloud from the eruption of Nyamurgira (DR Congo) in November 2011 with particle volume (and mass) concentrations similar to those deep into the LMS, see measurements 26, 27 and 28 in Fig. 8a (red vertical scale). These measurements together with 29 and 32 have $C_{\mathrm{V}} / C_{\mathrm{m}}$ ratios of 0.69 , $0.79,0.80,0.90$ and $1.3 \mathrm{~cm}^{3} \mathrm{~g}^{-1}$. The low $C_{\mathrm{V}} / C_{\mathrm{m}}$ ratios together with the size distributions of the measurements in the fresh volcanic cloud thus indicate some particle volume outside the OPC measurement range. All the measurements from the extratropical UT (Fig. 8b) have size distributions that indicate particle volume outside the lower size limit. However, the size distributions alone cannot explain variability in the $C_{\mathrm{V}} / C_{\mathrm{m}}$ ratio of $0.77-1.4 \mathrm{~cm}^{3} \mathrm{~g}^{-1}$, for example
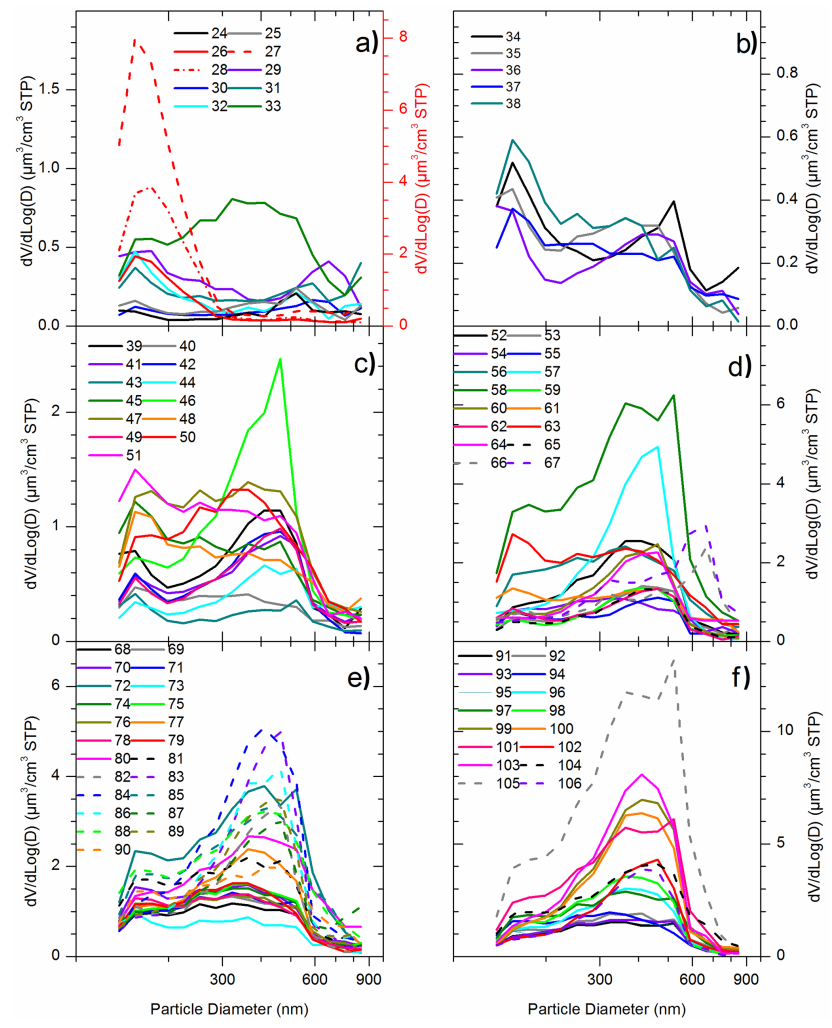

Figure 8. Particle volume distributions from the OPC for measurements without influence from clouds, high crustal or carbonaceous fractions. The legends show measurement number. (a) Tropics middle troposphere. Measurements 26-28 are shown on the axis to the right. (b) Extratropical UT (PV $<1.5$ PVU). (c) Tropopause region $(1.5<\mathrm{PV}<3 \mathrm{PVU})$. (d) $\mathrm{LMS} 3<\mathrm{PV}<5 \mathrm{PVU}$. (e) $\mathrm{LMS}$ $5<$ PV $<7$ PVU. (f) LMS PV $>7$ PVU.

distributions 34 and 38 (the smallest and largest $C_{\mathrm{V}} / C_{\mathrm{m}}$ ratio in this group) are similar both in terms of the distribution of small particles and relative particle volume for large particles. Measurements from the tropopause region (Fig. 8c) in some cases, in particular measurements 40, 43, 45 and 51, show significant concentration in the two lowest OPC channels without a dominant mode of larger particles. The respective $C_{\mathrm{V}} / C_{\mathrm{m}}$ ratios are $0.83,0.89,1.0$ and $1.2 \mathrm{~cm}^{3} \mathrm{~g}^{-1}$. All the measurement numbers are arranged in order of increasing $C_{\mathrm{V}} / C_{\mathrm{m}}$ ratio in each of Fig. 8a-f. Presence of particles outside the lower size limit thus cannot explain the variability in the $C_{\mathrm{V}} / C_{\mathrm{m}}$ ratio for measurements in the tropopause region. Finally, in Fig. 8d-f it can be seen that problems with particle volume outside the lower particle size limit are minor for the LMS aerosol. In conclusion it is clear that most size distributions from the MT tropics and the UT extratropics, and some of those from the tropopause region, indicate particle volume outside the lower size limit of the OPC, although it is not a major factor behind the variability of the $C_{\mathrm{V}} / C_{\mathrm{m}}$ ratio. Measurements taken in the LMS do not indicate this problem. 
In addition to investigating the conditions at the lower and upper size limit of the OPC, patterns associated with the volume mean diameter (VMD) will be examined. Figure 9 shows the $C_{\mathrm{V}} / C_{\mathrm{m}}$ ratio related to the VMD. There is no clear correlation between these parameters for the tropospheric and tropopause region measurements. For measurements taken in the LMS weak correlation is found in the PV range 3-5 PVU, whereas the 5-7 PVU and PV > 7 PVU ranges show a clear correlation, i.e. when VMD increases from 270 to $360 \mathrm{~nm}$ (where most of these measurements are found) the $C_{\mathrm{V}} / C_{\mathrm{m}}$ ratio in the LMS increases from 0.7 to $1.2 \mathrm{~cm}^{3} \mathrm{~g}^{-1}$. Two of the measurements (red stars) in Fig. 9 are the two outliers (measurements 21 and 22 in Fig. 7) where no reason for the deviation could be found. Figure 9 indicates that the VMD is important for the observed deviation. As already pointed out, LMS size distributions show no sign of problems with the lower or upper size limits of the OPC measurements. However, the OPC response to particle size needs to be considered. Besides dependence on composition (refractive index) and particle shape, the calibration curve for a given composition is complicated. The range $0.7-$ $1.2 \mathrm{~cm}^{3} \mathrm{~g}^{-1}$ in $C_{\mathrm{V}} / C_{\mathrm{m}}$ ratio corresponds to approximately $\pm 25 \%$ around the central value. If for the present, we disregard problems with the aerosol sampling and analysis this would indicate $25 \%$ particle volume measurement uncertainty, corresponding to a range of a modest $8 \%$ in terms of particle diameter for particles deep into the LMS.

\subsection{Problems in aerosol sampling and analysis}

It is clear that problems in the aerosol sampling were responsible for some of the outliers with respect to the $C_{\mathrm{V}} / C_{\mathrm{m}}$ ratio. The aerosol sampler collection efficiency shows excellent characteristics for liquid particles (Nguyen et al., 2006) and the errors from the PIXE and PESA analyses are small. However, solid particles could affect the sampling efficiency. Therefore all sample images not already dealt with in the previous sections (i.e. Figs. 4-7) will be investigated with respect to deposition pattern to find out to what degree the sampling suffered from losses.

Figure 10 shows the aerosol deposits of the samples taken in the tropical middle troposphere, the extratropical upper troposphere and the tropopause region. Ten tropical samples do not belong to the categories of outliers that were presented in Sect. 3.1. The aerosol sampling in the tropics usually worked well with seven QI $=0$ (i.e. deposit types 1.1, 1.2, 2.1 and 2.2) samples and three samples with $\mathrm{QI}=1$ (deposit type 3.1), whereas none of the samples showed indications of severe losses ( $\mathrm{QI}=2$; deposit types 2.3, 3.2, 3.3 and 4). Only five samples in Fig. 10 were taken in the extratropical UT. Three showed no signs of losses, one indicated minor losses and one major losses. Out of the 13 samples taken in the tropopause region, six showed no signs of losses, six minor losses and one sample indicated major losses. Overall, of

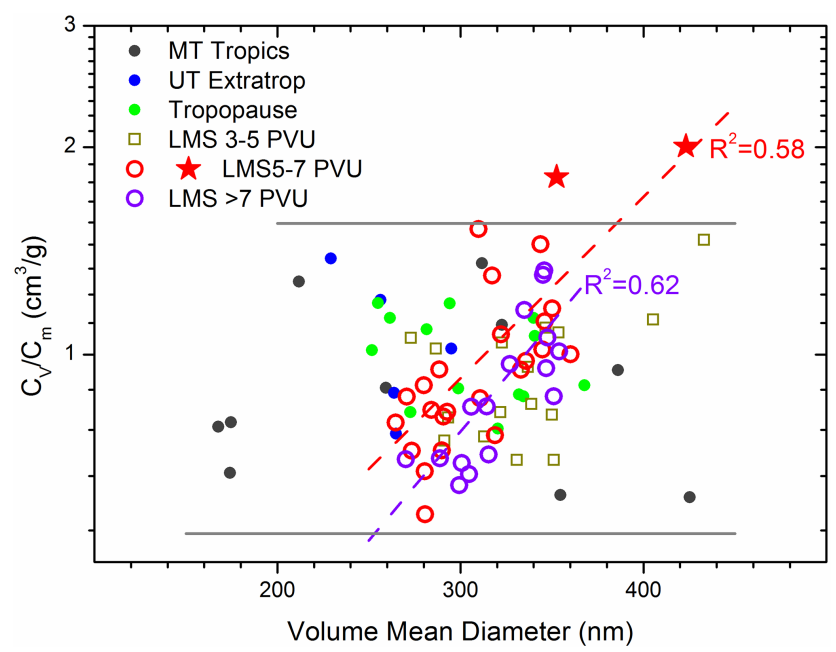

Figure 9. Dependence on volume mean diameter of the ratio of particle volume concentration $\left(C_{\mathrm{V}}\right.$, from the OPC) to mass concentration $\left(C_{\mathrm{m}}\right.$, from the aerosol samples). Purple and red lines are exponential fits to PV $>7$ PVU and $5<$ PV < 7 PVU data, respectively. Red stars are measurements classified as outliers where no explanation could be found in Sect. 3.1.

the 28 samples from these three sampling regions 57,36 and $7 \%$ had QIs 0,1 and 2, respectively.

The stratospheric samples are displayed in Fig. 11. Deposits with filaments wetting the surface of the polyimide film become more common in the stratosphere. Out of the 16 samples from the lowest stratospheric level, $3<\mathrm{PV}<5$ PVU (Fig. 11), 12 show no signs of losses $(\mathrm{QI}=0)$, three show minor losses and one indicates significant losses $(\mathrm{QI}=2)$. Deeper into the stratosphere, the PV range 5-7 PVU, 23 samples are available. Seventeen are of $\mathrm{QI}=0$, three of $\mathrm{QI}=1$ and three of $\mathrm{QI}=2$. Further up in the stratosphere, $\mathrm{PV}>7 \mathrm{PVU}$, 15 out of 16 have $\mathrm{QI}=0$ and the only sample with $\mathrm{QI}=2$ shows wetting of the sampling substrate that is deemed to cause significant losses (type 2.3). Together the samples from the three stratospheric sampling levels have QI values of 0,1 and 2 in 80,11 and $9 \%$ of the cases. Thus the fraction of the samples with major sampling problems is similar in the troposphere/tropopause and stratosphere, whereas a larger fraction of the stratospheric samples showed no signs of reduced collection efficiency.

Table 1 provides further overview of the classification with respect to aerosol deposit of the samples. Out of the total of 106 samples, 67 have deposit types that do not indicate losses in the sampling $(\mathrm{QI}=0), 21$ indicates minor losses $(\mathrm{QI}=1)$ and 18 more severe losses $(\mathrm{QI}=2)$. Eightythree samples do not belong to the outlier categories clouds, crust, large carbonaceous fraction or the outlier samples presented in Fig. 7. Out of these 83 samples $72 \%$ show no signs of losses $(\mathrm{QI}=0)$ and $8 \%$ have deposition patterns indicating major losses $(\mathrm{QI}=2)$. It is clear that $C_{\mathrm{V}} / C_{\mathrm{m}}$ shows a dependence on QI which is stronger when all samples are considered in comparison with when the four outlier 
Table 1. Classification based on photographic images of all samples.

\begin{tabular}{|c|c|c|c|c|}
\hline Category & Explanation & $\begin{array}{l}\text { No. Samples } \\
\text { Excl. outliers (All) }\end{array}$ & $\begin{array}{l}C_{\mathrm{V}} / C_{\mathrm{m}}^{\mathrm{b}} \\
\text { Excl. outliers (All) }\end{array}$ & $\mathrm{QI}^{\mathrm{c}}$ \\
\hline \multicolumn{5}{|c|}{ Type 1 - the expected pattern } \\
\hline 1.1 & medium-high-loaded samples & $26(30)$ & $0.86(0.91)$ & 0 \\
\hline 1.2 & low-loaded samples & $1(3)$ & {$[0.63](0.45)$} & 0 \\
\hline \multicolumn{5}{|c|}{ Type 2 - wetting of sampling substrate by liquid } \\
\hline 2.1 & wetting only within beam area & $28(29)$ & $0.89(0.92)$ & 0 \\
\hline 2.2 & minor wetting outside beam area & $5(5)$ & $0.89(0.89)$ & 0 \\
\hline 2.3 & considerable wetting outside beam area & $1(1)$ & {$[1.3(1.3)]$} & 2 \\
\hline \multicolumn{5}{|c|}{ Type 3 - secondary deposition pattern } \\
\hline 3.1 & central spot visible & $16(21)$ & $1.0(1.1)$ & 1 \\
\hline 3.2 & cross visible & $3(7)$ & $1.1(1.5)$ & 2 \\
\hline 3.3 & cross clearly visible & $1(3)$ & {$[1.1](2.4)$} & 2 \\
\hline \multicolumn{5}{|c|}{ Type 4 - large number of particles outside main deposit } \\
\hline 4 & & $2(7)$ & $1.4(2.6)$ & 2 \\
\hline \multicolumn{5}{|c|}{ Qualitative Indicator $\left(\mathrm{QI}^{\mathrm{c}}\right)$} \\
\hline 0 & types $1.1,1.2,2.1,2.2$ & $60(67)$ & $0.87(0.88)$ & 0 \\
\hline 1 & type 3.1 & $16(21)$ & $1.0(1.1)$ & 1 \\
\hline 2 & types $2.3,3.2,3.3,4$ & $7(18)$ & $1.2(2.0)$ & 2 \\
\hline All QI & all types & $83(106)$ & $0.93(1.1)$ & All \\
\hline
\end{tabular}

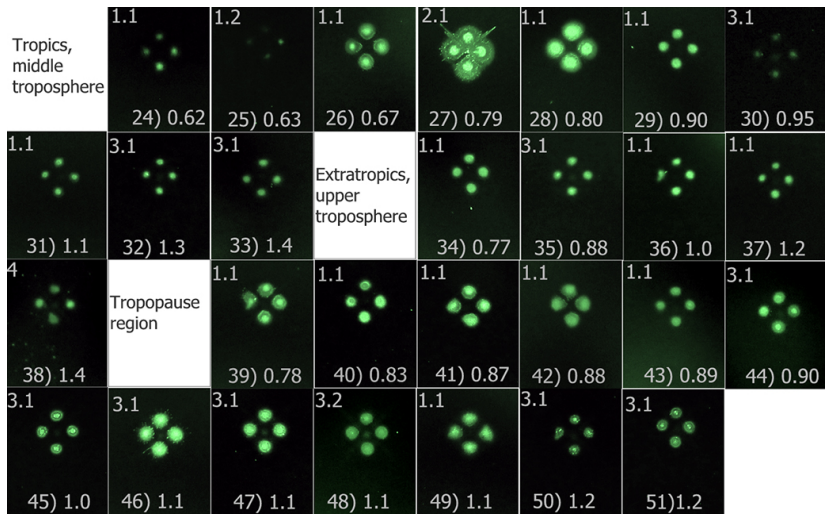

Figure 10. Photographic images of particle deposition patterns for middle troposphere tropics, extratropical upper troposphere and tropopause region samples not presented in Figs. 4-7. The upper left corner of each image shows the classification code of the deposit according to Table 1, and in the lower part sample number and $C_{\mathrm{V}} / C_{\mathrm{m}}\left(\mathrm{cm}^{3} \mathrm{~g}^{-1}\right)$ are shown. The bright lines in the image of sample 43 are caused by reflection in wrinkles present in this polyimide film.

categories are excluded see Table 1 . The average $C_{\mathrm{V}} / C_{\mathrm{m}}$ of the latter samples belonging with $\mathrm{QI}=0$ is $0.87 \mathrm{~cm}^{3} \mathrm{~g}^{-1}$. The average of all the 83 samples is $0.93 \mathrm{~cm}^{3} \mathrm{~g}^{-1}$, implying that the 23 samples with $\mathrm{QI}=1$ and $\mathrm{QI}=2$ increase the average $C_{\mathrm{V}} / C_{\mathrm{m}}$ by $6 \%$.
It is clear that the deposition pattern based on qualitative classification of the samples in part can explain variability in the $C_{\mathrm{V}} / C_{\mathrm{m}}$ ratio. Thereto we will briefly compare these results with measurements outside the regular $5.5 \mathrm{~mm}$ diameter proton beam used for quantitative analysis as explained in Sect. 2.1. Figure 12a shows the ratio of estimated, undetected sulfur mass outside the beam area of $5.5 \mathrm{~mm}$ diameter and the mass detected within the beam area, $m_{\mathrm{udet}} / m_{\mathrm{det}}$, in relation to particulate $S$ concentration. Small, filled symbols indicate that particulate $S$ was not detected in the two blank spots. These samples are represented by half the detection limit. It can be seen that particulate $\mathrm{S}$ could not be detected in the blank spots for samples with $\mathrm{QI}=0$ when the concentration was less than $100 \mathrm{ng} \mathrm{m}^{-3}$ STP. This is also true for most of the $\mathrm{QI}=1$ samples (type 3.1 ), whereas most of the $\mathrm{QI}=2$ samples show detection with high $m_{\mathrm{udet}} / m_{\mathrm{det}}$ ratio in that concentration range. For samples with particulate $S$ concentration higher than $100 \mathrm{ng} \mathrm{m}^{-3} \mathrm{STP}$ the $m_{\mathrm{udet}} / m_{\mathrm{det}}$ is low with a few exceptions. When relating $m_{\mathrm{udet}} / m_{\mathrm{det}}$ to the $C_{\mathrm{V}} / C_{\mathrm{m}}$ ratio for the samples where particulate $\mathrm{S}$ was detected in the blank spots a high degree of consistency can be found (Fig. 12b). $m_{\text {udet }} / m_{\text {det }}$ is in all but one case low when the $C_{\mathrm{V}} / C_{\mathrm{m}}$ ratio is low, and the deposit types are to a high degree of $\mathrm{QI}=0$ and 1 . In the other end both the parameters usually are high and almost all samples have $\mathrm{QI}=2$. The agreement between the different measures further supports the consistency of the two different CARIBIC aerosol 


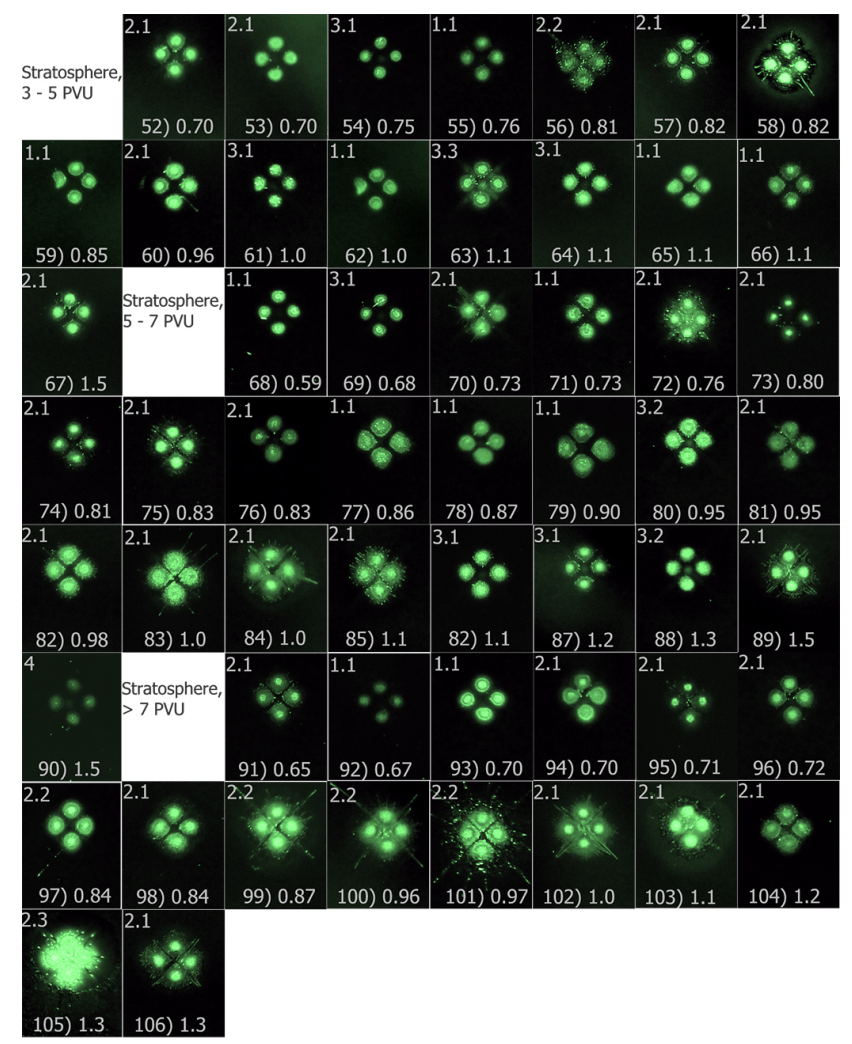

Figure 11. Photographic images of particle deposition patterns for stratospheric samples not presented in Figs. 4-7. Upper left corner of each image shows the classification code of the deposit according to Table 1 , and in the lower part are sample number and $C_{\mathrm{V}} / C_{\mathrm{m}}$ $\left(\mathrm{cm}^{3} \mathrm{~g}^{-1}\right)$.

measurement methods. The $m_{\mathrm{udet}} / m_{\mathrm{det}}$ ratio also provides an internal measure on the quality of a sample with respect to non-ideal effects in sampling with impactors.

\subsection{Apparent particle density}

To avoid bias from the outlier categories they are not retained in the data set used to further investigate the relation between the particle volume from the OPC and the mass from the sampling and analysis. The 83 measurements that did not belong to the outlier categories were all in the $C_{\mathrm{V}} / C_{\mathrm{m}}$ range of $0.55-1.55 \mathrm{~cm}^{3} \mathrm{~g}^{-1}$. Figure 13 shows $C_{\mathrm{V}}$ related to $C_{\mathrm{m}}$. It is obvious that these measurements correlate well over approximately a factor of 50 in $C_{\mathrm{m}}$ and $C_{\mathrm{V}}$ ranges. The relative spread in the data (logarithmic scale) is essentially independent of the concentration, implying causes other than statistical for the variability within the $0.55-1.55 \mathrm{~cm}^{3} \mathrm{~g} C_{\mathrm{V}} / C_{\mathrm{m}}$ range. By computing the geometric average (for consistency not the arithmetic average) of the ratio between $C_{\mathrm{m}}$ and $C_{\mathrm{V}}$ an estimate of the density of the aerosol particles is obtained. This apparent particle density becomes $1.08 \mathrm{~g} \mathrm{~cm}^{-3}$. It is clear that non-ideal sampling affected some of the measurements. Removing these measurements result in the density
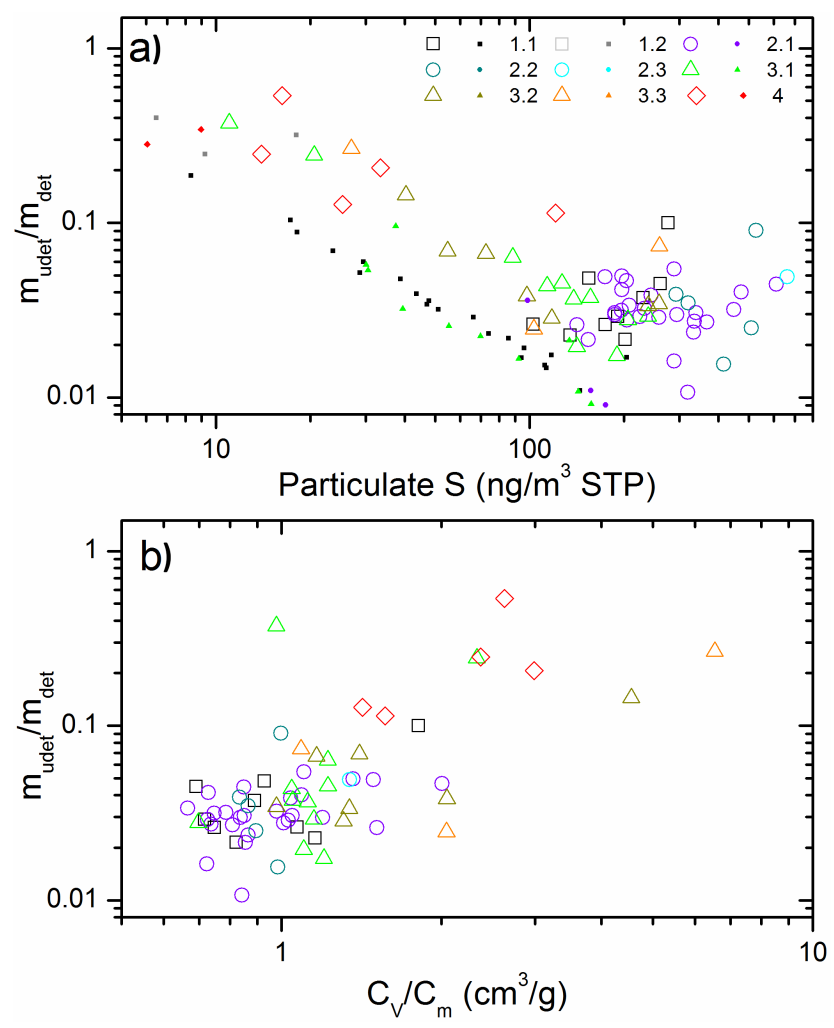

Figure 12. Ratio of estimated particulate sulphur mass outside the analytical beam $\left(m_{\text {udet }}\right)$ to detected mass $\left(m_{\text {det }}\right)$ related to $(\mathbf{a})$ atmospheric particulate sulphur concentration and (b) the ratio total particle volume from the OPC $\left(C_{\mathrm{V}}\right)$ and total mass from the analyses of the aerosol samples $\left(C_{\mathrm{m}}\right)$. Particulate sulphur was detected in the analytical area of all samples. Open samples show analyses where sulphur was detected also outside the analytical area, whereas the small, closed symbols show samples where sulphur was not detected.

$1.15 \mathrm{~g} \mathrm{~cm}^{-3}$. The main components of the UT/LMS aerosol are sulphurous and carbonaceous aerosol. Occasionally the aerosol also contains a significant crustal fraction. The density of pure sulphuric acid is $1.84 \mathrm{~g} \mathrm{~cm}^{-3}$, which could be somewhat lowered by mixing with water. Other possible forms of sulphate are ammonium bisulphate and ammonium sulphate with densities of 1.78 and $1.77 \mathrm{~g} \mathrm{~cm}^{-3}$, respectively. The $\mathrm{C} / \mathrm{S}$ elemental concentration ratio varies between 0.3 and 30 in the samples of this study. The carbonaceous fraction is to a large degree organic (Friberg et al., 2014). Probably the organic component acts as to lower the density of the particles, but likely not down to $1.15 \mathrm{~g} \mathrm{~cm}^{-3}$. Previous measurements at remote location (Saarikoski et al., 2005; Kannosto et al., 2008) and an urban location (Hu et al., 2012) estimate the density of sub-micrometer atmospheric particles to approximately $1.5 \mathrm{~g} \mathrm{~cm}^{-3}$. The apparent density of $1.15 \mathrm{~g} \mathrm{~cm}^{-3}$ from this study is $30 \%$ lower, thus calling for a discussion of the patterns behind this apparent density. 


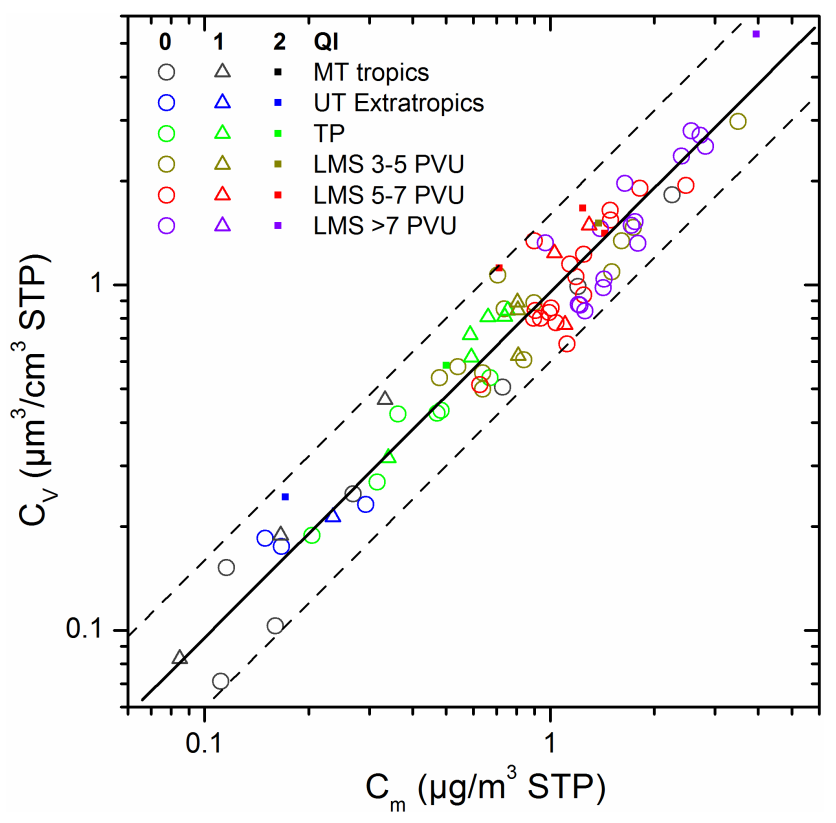

Figure 13. Particle volume concentration obtained from the OPC as a function of mass concentration from the aerosol samples taken at three PV levels in the stratosphere, the tropopause, the extratropical UT and the middle troposphere of the tropics. The colour of the symbols shows sampling location and the shape shows the quality indicator (QI) of the samples.

The measurements with the OPC and the elemental analyses of the samples are undertaken at approximately the same temperature. However, the analyses are undertaken in high vacuum, which can induce losses of organic material from the samples (Sect. 2.1). The composition and therefore the volatility of the organic fraction of the aerosol are not known. Therefore the losses during analysis cannot be estimated directly. The average carbon-to-sulphate mass ratio in samples of this study is 0.37 , the ratio being higher in the troposphere (0.75) than in the stratosphere $(0.26)$. To increase the apparent density to a value of $1.5 \mathrm{~g} \mathrm{~cm}^{-3}$ by increasing the carbon concentration in an attempt to reach more plausible value, the carbon concentrations need to be multiplied by approximately 2 . This would increase the carbon-to-sulphate mass ratio average over all samples to 0.8 , and for stratospheric samples carbon to sulphate mass ratio would become larger than 0.5 , which is not in line with studies based on another analytical method (Murphy et al., 2006, 2007). In addition, studies of volcanic aerosol based on CARIBIC aerosol samples (Martinsson et al., 2009) agree well with studies based on other methods (Schmale et al., 2010; Carn et al., 2011) in the relation between the carbonaceous and sulphurous fractions of the aerosol. The increase of the carbonaceous fraction to reach $1.5 \mathrm{~g} \mathrm{~cm}^{-3}$ density would bring our volcanic measurements into disagreement with the mentioned other studies.
Losses of organic material would thus only explain part of the difference to previous observations at other locations. The uncertainties of the mass from the aerosol samples disregarding evaporative losses, is estimated to $12 \%$. The combined uncertainty in the number concentration and particle size combine to $50 \%$ uncertainty in the particle volume determinations from the OPC. Taking the combined uncertainties of the two measurements into account, the observed apparent density is not deviating from previous observations.

\section{Conclusions}

Two aerosol measurement methods aboard the CARIBIC platform for studies of the upper troposphere (UT) and the lowermost stratosphere (LMS) were compared. The particle volume concentration $\left(C_{\mathrm{V}}\right)$ obtained from the CARIBIC optical particle counter (OPC) and total mass concentrations $\left(C_{\mathrm{m}}\right)$ obtained from aerosol samples analysed for all major and several minor constituents by ion beam analysis were compared by forming the ratio of the two measurements $\left(C_{\mathrm{V}} / C_{\mathrm{m}}\right) .89$ of the 106 measurements investigated have a $C_{\mathrm{V}} / C_{\mathrm{m}}$ ratio confined to a rather narrow interval of 0.55 $1.55 \mathrm{~cm}^{3} \mathrm{~g}^{-1}$. Problems in the aerosol sampling were identified by photographic images of the deposition pattern, where secondary deposits indicate non-ideal sampling characteristics. Out of the 17 measurements outside the usual $C_{\mathrm{V}} / C_{\mathrm{m}}$ range of $0.55-1.55 \mathrm{~cm}^{3} \mathrm{~g}^{-1}$, six were connected with ice particles forming artificial particles in the inlet severely affecting total particle volume collected by the OPC and, in most cases, the aerosol deposition pattern of the samples. Three of the outliers were caused by non-ideal sampling of crustal particles and to some degree by problems with refractive index of the OPC and mismatch of the size ranges of the two measurements. Two of the measurements that were dominated by carbonaceous aerosol were below the usual $C_{\mathrm{V}} / C_{\mathrm{m}}$ range because part of the size distribution was below the lower size limit of the OPC, and, probably due to a mismatch of the refractive index of the actual particles and that used in the OPC calibration. Of the remaining six measurements three showed poor sampling efficiency and the fourth mismatch in size range. The remaining two samples could be associated with the complicated relation between particle size and OPC signal, which was manifested by a correlation between particle volume mean diameter and the $C_{\mathrm{V}} / C_{\mathrm{m}}$ ratio.

$84 \%$ of the measurements have $C_{\mathrm{V}} / C_{\mathrm{m}}$ ratios within the range of $0.55-1.55 \mathrm{~cm}^{3} \mathrm{~g}^{-1}$. The volume and mass concentrations span approximately a factor of 50 without significant change in relative residuals, thus indicating causes other than statistical for the variability. From this correlation the apparent average density of the particles was estimated to $1.15 \mathrm{~g} \mathrm{~cm}^{-3}$ after removal of $6 \%$ bias from non-ideal sampling effects of the impactor. This apparent particle density is lower than previous estimates by $30 \%$. The combined 
uncertainties of the two methods, however, accommodate this difference.

Visual inspection and classification of the samples aerosol deposits was found to be an efficient means to identify samples where non-ideal sampling appeared, which was corroborated by the $C_{\mathrm{V}} / C_{\mathrm{m}}$ ratio. The analytical methodology utilizing blank spots of the sample provided further insights to the problem of non-ideal impactor sampling. This method can be applied routinely with minimal effort, thus providing the means to significantly reduce problems, however moderate in this study, from impactor sampling imperfections.

In conclusion, two methods based on widely different principles were inter-compared over a range of a factor of 50 in atmospheric aerosol concentration. The composition expressed as the ratio between the two main aerosol components in the aerosol particles, carbon and sulphur, varied over a range of a factor 100 thus further illustrating the variable condition in the UT/LMS. Except for a few outliers that could be connected with ice clouds, crust, size range mismatch or non-ideal sampling, a strong correlation between the two methods indicates that in most cases the CARIBIC aerosol sampling/analysis and OPC produce consistent and reliable results. This implies that the CARIBIC measurements with the OPC and the aerosol sampler can be combined to further understand the physical and chemical nature of the upper tropospheric and lowermost stratospheric aerosol.

Acknowledgements. We especially acknowledge C. Koeppel, D. S. Scharffe, S. Weber and all other members of the CARIBIC project. Lufthansa and Lufthansa Technik are gratefully acknowledged for enabling this scientific experiment. Financial support from the Swedish Research Council for Environments, Agricultural Sciences and Spatial Planning under grant 214-2009-613 is gratefully acknowledged.

Edited by: W. Maenhaut

\section{References}

Ammann, C. M., Meehl, G. A., Washington, W. M., and Zender, C. S.: A monthly and latitudinally varying volcanic forcing dataset in simulations of 20th century climate, Geophys. Res. Lett., 30, 1657, doi:10.1029/2003GL016875, 2003.

Andersson, S. M., Martinsson, B. G., Friberg, J., Brenninkmeijer, C. A. M., Rauthe-Schöch, A., Hermann, M., van Velthoven, P. F. J., and Zahn, A.: Composition and evolution of volcanic aerosol from eruptions of Kasatochi, Sarychev and Eyjafjallajökull in 2008-2010 based on CARIBIC observations, Atmos. Chem. Phys., 13, 1781-1796, doi:10.5194/acp-13-1781-2013, 2013.

Andreae, M. O. and Rosenfeld, D.: Aerosol-cloud-precipitation interactions, Part 1. The nature and sources of cloud-active aerosols, Earth-Sci. Rev., 89, 13-41, 2008.

Baker, A. K., Slemr, F., and Brenninkmeijer, C. A. M.: Analysis of non-methane hydrocarbons in air samples collected aboard the
CARIBIC passenger aircraft, Atmos. Meas. Tech., 3, 311-321, doi:10.5194/amt-3-311-2010, 2010.

Bauman, J. J., Russell, P. B., Geller, M. A., and Patrick, H.: A stratospheric aerosol climatology from SAGE II and CLAES measurements: 2. Results and comparisons, 1984-1999, J. Geophys. Res., 108, 4383, doi:10.1029/2002JD002993, 2003

Bohren, C. F. and Huffman, D. R.: Absorption and Scattering of Light by Small Particles, 1st Edn., p. 530, New York: John Wiley \& Sons, 1983.

Brenninkmeijer, C. A. M., Crutzen, P. J., Fischer, H., Güsten, H., Hans, W., Heinrich, G., Heintzenberg, J., Hermann, M., Immelmann, T., Kersting, D., Maiss, M., Nolle, M., Pitscheider, A., Pohlkamp, H., Scharffe, D., Specht, K., and Wiedensohler, A.: CARIBIC civil aircraft for global measurement of trace gases and aerosols in the tropopause region, J. Atmos. Ocean. Tech., 16, 1373-1383, 1999.

Brenninkmeijer, C. A. M., Crutzen, P., Boumard, F., Dauer, T., Dix, B., Ebinghaus, R., Filippi, D., Fischer, H., Franke, H., Frieß, U., Heintzenberg, J., Helleis, F., Hermann, M., Kock, H. H., Koeppel, C., Lelieveld, J., Leuenberger, M., Martinsson, B. G., Miemczyk, S., Moret, H. P., Nguyen, H. N., Nyfeler, P., Oram, D., O’Sullivan, D., Penkett, S., Platt, U., Pupek, M., Ramonet, M., Randa, B., Reichelt, M., Rhee, T. S., Rohwer, J., Rosenfeld, K., Scharffe, D., Schlager, H., Schumann, U., Slemr, F., Sprung, D., Stock, P., Thaler, R., Valentino, F., van Velthoven, P., Waibel, A., Wandel, A., Waschitschek, K., Wiedensohler, A., Xueref-Remy, I., Zahn, A., Zech, U., and Ziereis, H.: Civil Aircraft for the regular investigation of the atmosphere based on an instrumented container: The new CARIBIC system, Atmos. Chem. Phys., 7, 4953-4976, doi:10.5194/acp-7-4953-2007, 2007.

Carn, S. A., Froyd, K. D., Anderson, B. E., Wennberg, P., Crounse, J., Spencer, K., Dibb, J. E., Krotkov, N. A., Browell, E. V., Hair, J. W., Diskin, G., Sachse, G., and Vay, S. A.: In situ measurements of tropospheric volcanic plumes in Equador and Colombia during TC ${ }^{4}$, J. Geophys. Res., 116, D00J24, doi:10.1029/2010JD014718, 2011.

Deiters, U. K. and Randzio, S. L.: A combined determination of phase diagrams of assymetric binary mixtures by equations of state and transitiometry, Fluid Phase Equilibr., 260, 87-97, 2007

de Reus, M., Ström, J., Kulmala, M., Pirjola, L., Lelieveld, J., Schiller, C., and Zöger, M.: Airborne aerosol measurements in the tropopause region and the dependence of new particle formation on preexisting particle number concentration, J. Geophys. Res., 103, 31255-31263, 1998.

Deshler, T., Hervig, M. E., Hofmann, D. J., Rosen, J. M., and Liley, J. B.: Thirty years of in situ stratospheric aerosol size distribution measurements from Laramie, Wyoming $\left(41^{\circ} \mathrm{N}\right)$, using balloon-borne instruments, J. Geophys. Res., 108, 4167, doi:10.1029/2002JD002514, 2003.

Dibb, J. E., Talbot, R. W., and Scheuer, E. M.: Composition and distribution of aerosols over the North Atlantic during the subsonic assessment ozone and nitrogen oxide experiment (SONEX), J. Geophys. Res., 105, 3709-3717, doi:10.1029/1999JD900424, 2000.

Dirksen, R. J., Boersma, K. F., de Laat, J., Stammes, P., van det Werf, G. R., Martin, M. V., and Kelder, H. M.: An aerosol boomerang: Rapid around-the-world transport of smoke from the December 2006 Australian forest fires observed from space, J. Geophys. Res., 114, D21201, doi:10.1029/2009JD012360, 2009. 
Eguchi, K., Uno, I., Yumimoto, K., Takemura, T., Shimizu, A., Sugimoto, N., and Liu, Z.: Trans-pacific dust transport: integrated analysis of NASA/CALIPSO and a global aerosol transport model, Atmos. Chem. Phys., 9, 3137-3145, doi:10.5194/acp-93137-2009, 2009.

Friberg, J., Martinsson, B. G., Andersson, S. M., Brenninkmeijer, C. A. M., Hermann, M., van Velthoven, P. J. F., and Zahn, A.: Sources of increase in LMS sulfurous and carbonaceous aerosol background concentrations during 1999-2008 from CARIBIC flights, Tellus B, 66, 23428, doi:10.3402/tellusb.v66.23428, 2014

Fromm, M., Lindsey, D. T., Servranckx, R., Yue, G., Trickl, T., Sica, R., Douchet, P., and Godin-Beekmann, S.: The untold story of pyrocumulonimbus, B. Am. Meteorol. Soc., 91, 1193-1209, doi:10.1175/2010BAMS3004.1, 2010.

Gislason, S. R., Hassenkam, T., Nedel, S., Bovet, N., Eiriksdottir, E. S., Alfredsson, H. A., Hem, C. P., Balogh, Z. I., Dideriksen, K., Oskarsson, N., Sigfusson, B., Larsen, G., and Stripp, L. S.: Characterization of Eyjafjallajökull volcanic ash particles and protocol for rapid risk assessment, P. Natl. Acad. Sci. USA, 108, 7307-7312, 2011.

Hermann, M., Heintzenberg, J., Wiedensohler, A., Zahn, A., Heinrich, G., and Brenninkmeijer, C. A. M.: Meridional distributions of aerosol particle number concentrations in the upper troposphere and lower stratosphere obtained by Civil Aircraft for Regular Investigation of the Atmosphere Based on an Instrument Container (CARIBIC) flights, J. Geophys. Res., 108, 4114, doi:10.1029/2001JD001077, 2003.

Hervig, M. and Deshler, T.: Evaluation of aerosol measurements from SAGE II, HALOE, and balloon-borne optical particle counters, J. Geophys. Res., 107, 4031, doi:10.1029/2001JD000703, 2002

Hoerling, M. P., Schaak, T. K., and Lenzen, A. J.: Global objective tropopause analysis, Mon. Weahter Rev., 119, 1816-1831, 1991.

Hoinka, K. P.: The tropopause discovery, definition and demarcation, Meteorol. Z., 6, 281-303, 1997.

Hu, M., Peng, J., Sun, K., Yue, D., Guo, S., Wiedensohler, A., and $\mathrm{Wu}, \mathrm{Z}$.: Estimation of size-resolved ambient particle density based on the measurement of aerosol number, mass and chemical size distributions in the winter in Beijing, Environ. Sci. Technol., 46, 9941-9947, doi:10.1021/es204073t, 2012.

Huebert, B., Bertram, T., Kline, J., Howell, S., Eatough D., and Blomquist, B.: Measurements of organic and elemental carbon in Asian outflow during ACE-Asia from the NSF/NCAR C-130, J. Geophys. Res., 109, D19S11, doi:10.1029/2004JD004700, 2004.

IPCC: Climate Change 2013: The Physical Science Basis. Contribution of working group I to the fifth assessment report of the Intergovernmental Panel on Climate Change, edited by: Stocker, T. F., Qin, D., Plattner, G.-K., Tignor, M. M. B., Allen, S. K., Boschung, J., Nauels, A., Xia, Y., Bex, V., and Midgley, P. M., Cambridge University Press, United Kingdom and New York, NY, USA, 1535 pp., 2013.

Johansson, S. A. E. and Campbell, J. L.: PIXE: A novel technique for elemental analysis, 347 pp., John Wiley, Hoboken, N. J., 1988.

Kannosto, J., Virtanen, A., Lemmetty, M., Mäkelä, J. M., Keskinen, J., Junninen, H., Hussein, T., Aalto, P., and Kulmala, M.: Mode resolved density of atmospheric aerosol particles, Atmos. Chem. Phys., 8, 5327-5337, doi:10.5194/acp-8-5327-2008, 2008.
Kojima, T., Buseck, P. R., Wilson, J. C., Reeves, J. M., and Mahoney, M. J.: Aerosol particles from tropical convective systems: Cloud tops and cirrus anvils, J. Geophys. Res., 109, D12201, doi:10.1029/2003JD004504, 2004.

Koop, T., Luo, B., Tsias, A., and Peter, T.: Water activity as the determinant for homogeneous ice nucleation in aqueous solutions, Nature, 406, 611-614, 2000

Korolev, A. V., Emery, E. F., Strapp, J. W., Cober, S. G., Isaac, G. A., Wasey, M., and Marcotte, D.: Small ice particles in tropospheric clouds: Fact or artifact?, B. Am. Meteorol. Soc., 92, 967-973, doi:10.1175/2010BAMS2935.1, 2011.

Martinsson, B. G.: An external beam PIXE/PESA setup for characterization of fine aerosols, Nucl. Instr. Meth. B, 22, 356-363, 1987.

Martinsson, B. G. and Hansson, H.-C.: Ion beam thermography - analysis of chemical compounds using ion beam techniques, Nucl. Instr. and Meth. B, 34, 203-208, 1988.

Martinsson, B. G., Papaspiropoulos, G., Heintzenberg, J., and Hermann, M.: Fine mode particulate sulphur in the tropopause region from intercontinental commercial flights, Geophys. Res. Lett., 28, 1175-1178, 2001.

Martinsson, B. G., Nguyen, H. N., Brenninkmeijer, C. A. M., Zahn, A., Heintzenberg, J., Hermann, M., and van Velthoven, P. F. J.: Characteristics and origin of lowermost stratospheric aerosol at northern midlatitudes under volcanically quiescent conditions based on CARIBIC observations, J. Geophys. Res., 110, D12201, doi:10.1029/2004JD005644, 2005.

Martinsson, B. G., Brenninkmeijer, C. A. M., Carn, S. A., Hermann, M., Heue, K.-P., van Velthoven, P. F. J., and Zahn, A.: Influence of the 2008 Kasatochi volcanic eruption on sulfurous and carbonaceous aerosol constituents in the lower stratosphere, Geophys. Res. Lett., 36, L12813, doi:10.1029/2009GL038735, 2009.

Mattis, I., Siefert, P., Müller, D., Tesche, M., Hiebesch, A., Kanitz, T., Schmidt, J., Finger, F., Wandinger, U., and Ansmann, A.: Volcanic aerosol layers observed with multiwavelength Raman lidar over central Europe in 2008-2009, J. Geophys Res., 115, D00L04, doi:10.1029/2009JD013472, 2010.

McCormick, M. P., Thomason, L. W., and Trepte, C. R.: Atmospheric effects of the Mt Pinatubo eruption, Nature, 373, 399404, 1995.

Mentes, B., Papaspiropoulos, G., and Martinsson, B. G.: Ion-beam thermography analysis of the $\mathrm{H}_{2} \mathrm{SO}_{4}-\left(\mathrm{NH}_{4}\right)_{2} \mathrm{SO}_{4}$ system in aerosol samples, Nucl. Instr. Meth. B, 168, 533-542, 2000.

Murphy, D. M., Thomson, D. S., and Mahoney, M. J.: In situ measurements of organics, meteoritic material, mercury, and other elements in aerosols at 5 to 19 kilometers, Science, 282, 5394, doi:10.1126/science.282.5394.1664, 1998.

Murphy, D. M., Cziczo, D. J., Hudson, P. K., Thomson, D. S., Wilson, J. C., Kojima, T., and Buseck, P. R.: Particle generation and resuspension in aircraft inlets when flying in clouds, Aerosol Sci. Technol., 38, 401-409, 2004.

Murphy, D. M., Cziczo, D. J., Froyd, K. D., Hudson, P. K., Matthew, B. M., Middlebrook, A. M., Peltier, R. E., Sullivan, A., Thomson, D. S., and Weber, R. J.: Single-particle mass spectrometry of tropospheric aerosol particles, J. Geophys. Res., 111, D23S32, doi:10.1029/2006JD007340, 2006.

Murphy, D. M., Cziczo, D. J., Hudson, P. K., and Thomson, D. S.: Carbonaceous material in aerosol particles in the lower strato- 
sphere and tropopause region, J. Geophys. Res., 112, D04203, doi:10.1029/2006JD007297, 2007.

Nguyen H. N. and Martinsson B. G.: Analysis of C, N and O in aerosol collected on an organic backing using internal blank measurements and variable beam size, Nucl. Instr. Meth. B, 264, 96$102,2007$.

Nguyen, H. N., Gudmundsson, A., and Martinsson, B. G.: Design and calibration of a multi-channel aerosol sampler for studies of the tropopause region from the CARIBIC platform, Aerosol Sci. Technol., 40, 649-655, 2006.

Nguyen, H. N., Martinsson, B. G., Wagner, J. B., Carlemalm, E., Ebert, M., Weinbruch, S., Brenninkmeijer, C. A. M., Heintzenberg, J., Hermann, M., Schuck, T., van Velthoven, P. F. J., and Zahn, A.: Chemical composition and morphology of individual aerosol particles from a CARIBIC fight at $10 \mathrm{~km}$ altitude between $50^{\circ} \mathrm{N}$ and $30^{\circ} \mathrm{S}$, J. Geophys. Res., 113, D23209, doi:10.1029/2008JD009956, 2008.

Oram, D. E., Mani, F. S., Laube, J. C., Newland, M. J., Reeves, C. E., Sturges, W. T., Penkett, S. A., Brenninkmeijer, C. A. M., Röckmann, T., and Fraser, P. J.: Long-term tropospheric trend of octafluorocyclobutane $\left(\mathrm{c}-\mathrm{C}_{4} \mathrm{~F}_{8}\right.$ or PFC-318), Atmos. Chem. Phys., 12, 261-269, doi:10.5194/acp-12-261-2012, 2012.

Pak, S. S., Liu, B. Y. H., and Rubow, K. L.: Effects of coating thickness on particle bounce in inertial impactors, Aerosol Sci. Technol., 16, 141-150, 1992

Papaspiropoulos, G., Mentes, B., Kristiansson, P., and Martinsson, B. G.: A high sensitivity elemental analysis methodology for upper tropospheric aerosol, Nucl. Instr. Meth. B, 150, 356-362, 1999.

Papaspiropoulos, G., Martinsson, B. G., Zahn, A., Brenninkmeijer, C. A. M., Hermann, M., Heintzenberg, J., Fischer, H., and van Velthoven, P. F. J.: Aerosol elemental concentrations in the tropopause region from intercontinental flights with the CARIBIC platform, J. Geophys. Res., 107, 4671, doi:10.1029/2002JD002344, 2002.

Pope III, C. A. and Dockery, D. W.: Health effects of fine particulate air pollution: Lines that connect, J. Air Waste Manage., 56, 709742, 2006

Rauthe-Schöch, A., Weigelt, A., Hermann, M., Martinsson, B. G., Baker, A. K., Heue, K.-P., Brenninkmeijer, C. A. M., Zahn, A., Scharffe, D., Eckhardt, S., Stohl, A., and van Velthoven, P. F. J.: CARIBIC aircraft measurements of Eyjafjallajökull volcanic clouds in April/May 2010, Atmos. Chem. Phys., 12, 879-902, doi:10.5194/acp-12-879-2012, 2012.

Rinsland, C. P., Yue, G. K., Gunson, M. R., Zander, R. and Abrams, M. C.: Mid-infrared extinction by sulphate aerosols from the Mt Pinatubo eruption, J. Quart. Radiat. Transfer, 52, 241-252, 1994.

Rosenfeld, D. and Woodley, W. L.: Deep convective clouds with sustained supercooled liquid water down to $-37.5^{\circ} \mathrm{C}$, Nature, 405, 440-442, 2000.

Saarikoski, S., Mäkälä, T., Hillamo, R., Aalto, P. P., Kerminen, V.-M., and Kulmala, M.: Physico-chemical characterization and mass closure of size-segregated atmospheric aerosols in Hyytiälä, Finland, Boreal Environ. Res., 10, 385-400, 2005.
Schmale, J., Schneider, J., Jurkat, T., Voight, C., Kalesse, H., Rautenhaus, M., Lichtenstern, M., Schlager, H., Ancellet, G., Arnold, F., Gerding, M., Mattis, I., Wendisch, M., and Borrmann, S.: Aerosol layers from the 2008 eruptions of Mount Okmok and Mount Kasatochi: In situ upper troposphere and lower stratosphere measurements of sulfate and organics over Europe, J. Geophys. Res., 115, D00L07, doi:10.1029/2009JD013628, 2010.

Schuck, T. J., Brenninkmeijer, C. A. M., Slemr, F., Xueref-Remy, I., and Zahn, A.: Greenhouse gas analysis of air samples collected onboard the CARIBIC passenger aircraft, Atmos. Meas. Tech., 2, 449-464, doi:10.5194/amt-2-449-2009, 2009.

Schumann, U., Weinzierl, B., Reitebuch, O., Schlager, H., Minikin, A., Forster, C., Baumann, R., Sailer, T., Graf, K., Mannstein, H., Voigt, C., Rahm, S., Simmet, R., Scheibe, M., Lichtenstern, M., Stock, P., Rüba, H., Schäuble, D., Tafferner, A., Rautenhaus, M., Gerz, T., Ziereis, H., Krautstrunk, M., Mallaun, C., Gayet, J.F., Lieke, K., Kandler, K., Ebert, M., Weinbruch, S., Stohl, A., Gasteiger, J., Groß, S., Freudenthaler, V., Wiegner, M., Ansmann, A., Tesche, M., Olafsson, H., and Sturm, K.: Airborne observations of the Eyjafjalla volcano ash cloud over Europe during air space closure in April and May 2010, Atmos. Chem. Phys., 11, 2245-2279, doi:10.5194/acp-11-2245-2011, 2011.

Schwartz, S. E., Charlson, R. J., Kahn, R. A., Ogren, J. A., and Rodhe, H.: Why hasn't earth warmed as much as expected?, J. Climate, 23, 2453-246, 2010.

Schwarz, J. P., Spackman, J. R., Gao, R. S., Watts, L. A., Stier, P., Schulz, M., Davis, S. M., Wofsy, S. C., and Fahey, D. W.: Global-scale black carbon profiles observed in the remote atmosphere and compared to models, Geophys. Res. Lett., 37, L18812, doi:10.1029/2010GL044372, 2010.

Solomon, S., Daniel, J. S., Neely III, R. R., Vernier, J.-P., Dutton, E. G., and Thomason, L. W.: The persistently variable "background" stratospheric aerosol layer and global climate change, Science, 333, 866-870, 2011.

Van de Hulst, H. C.: Light Scattering by Small Particles, 2nd Edn., 23 pp., 124-126, New York: Dover Publications, ISBN: 0-48664228-3, 1981.

Vernier, J.-P., Thomason, L. W., Pommereau, J.-P., Bourassa, A., Pelon, J., Garnier, A., Hauchecorne, A., Blanot, L., Trepte, C., Degenstein, D., and Vargas, F.: Major influence of tropical volcanic eruptions on the stratospheric aerosol layer during the last decade, Geophys. Res. Lett., 38, L12807, doi:10.1029/2011GL047563, 2011.

Weaver, B. L. and Tarney, J.: Empirical approach to estimating the composition of the continental crust, Nature, 310, 575-577, 1984.

Xu, L., Okada, K., Iwasaka, Y., Hara, K., Okuhara, Y., Tsutsumi, Y., and Shi, G.: The composition of individual aerosol particle in the troposphereand stratosphere over Xianghe $\left(39.45^{\circ} \mathrm{N}, 117.0^{\circ} \mathrm{E}\right)$, China, Atmos. Environ., 35, 3145-3153, doi:10.1016/S13522310(00)00532-X, 2001. 